\title{
Nanodiagnosis and Nanotreatment of Cardiovascular Diseases: An Overview
}

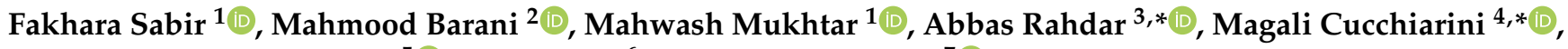 \\ Muhammad Nadeem Zafar ${ }^{5}$ (D), Tapan Behl ${ }^{6}$ and Simona Bungau ${ }^{7}$ (D) \\ 1 Faculty of Pharmacy, Institute of Pharmaceutical Technology and Regulatory Affairs, University of Szeged, \\ 6720 Szeged, Hungary; fakhra.sabir@gmail.com (F.S.); mukhtar.mahwash@pharm.u-szeged.hu (M.M.) \\ 2 Department of Chemistry, Shahid Bahonar University of Kerman, Kerman 76169-14111, Iran; \\ mahmoodbarani7@gmail.com \\ 3 Department of Physics, Faculty of Science, University of Zabol, Zabol 538-98615, Iran \\ 4 Center of Experimental Orthopaedics, Saarland University Medical Center, D-66421 Homburg, Germany \\ 5 Department of Chemistry, University of Gujrat, Gujrat 50700, Pakistan; znadeempk@gmail.com \\ 6 Chitkara College of Pharmacy, Chitkara University, Punjab 140401, India; tapanbehl31@gmail.com \\ 7 Department of Pharmacy, Faculty of Medicine and Pharmacy, University of Oradea, 410028 Oradea, Romania; \\ sbungau@uoradea.ro \\ * Correspondence: a.rahdar@uoz.ac.ir (A.R.); mmcucchiarini@hotmail.com (M.C.)
}

\section{check for}

updates

Citation: Sabir, F.; Barani, M.; Mukhtar, M.; Rahdar, A.; Cucchiarini, M.; Zafar, M.N.; Behl, T.; Bungau, S. Nanodiagnosis and Nanotreatment of Cardiovascular Diseases: An Overview. Chemosensors 2021, 9, 67. https://doi.org/10.3390/ chemosensors 9040067

\section{Academic Editors:}

Nicole Jaffrezic-Renault and Pilar López-Cornejo

Received: 13 February 2021

Accepted: 26 March 2021

Published: 30 March 2021

Publisher's Note: MDPI stays neutral with regard to jurisdictional claims in published maps and institutional affiliations.

Copyright: (c) 2021 by the authors. Licensee MDPI, Basel, Switzerland. This article is an open access article distributed under the terms and conditions of the Creative Commons Attribution (CC BY) license (https:/ / creativecommons.org/licenses/by/ $4.0 /)$.

\begin{abstract}
Cardiovascular diseases (CVDs) are the world's leading cause of mortality and represent a large contributor to the costs of medical care. Although tremendous progress has been made for the diagnosis of CVDs, there is an important need for more effective early diagnosis and the design of novel diagnostic methods. The diagnosis of CVDs generally relies on signs and symptoms depending on molecular imaging (MI) or on CVD-associated biomarkers. For early-stage CVDs, however, the reliability, specificity, and accuracy of the analysis is still problematic. Because of their unique chemical and physical properties, nanomaterial systems have been recognized as potential candidates to enhance the functional use of diagnostic instruments. Nanomaterials such as gold nanoparticles, carbon nanotubes, quantum dots, lipids, and polymeric nanoparticles represent novel sources to target CVDs. The special properties of nanomaterials including surface energy and topographies actively enhance the cellular response within CVDs. The availability of newly advanced techniques in nanomaterial science opens new avenues for the targeting of CVDs. The successful application of nanomaterials for CVDs needs a detailed understanding of both the disease and targeting moieties.
\end{abstract}

Keywords: nanotechnology; diagnosis; treatment; cardiovascular diseases

\section{Introduction}

Cardiovascular diseases (CVDs) are considered a major cause of mortality worldwide. According to the World Health Organization, CVDs led to the death of about 17.9 million people in 2016, contributing to $31 \%$ of total global deaths [1]. CVDs represent an economic burden for low- and middle-income countries as many people die at young age in their active time [2]. The heart consists of a variety of cells including cardiac fibroblasts, cardiomyocytes, neural cells, and vascular cells. Any dysfunction or abnormality in these endothelial, smooth, or connective cells results in CVDs [3]. The term CVDs encompasses a diverse set of disorders related to the heart which include ischemic heart disease, cerebrovascular diseases, arrhythmia, Marfan syndrome, thrombosis, pericardial disease, heart failure, stroke, vascular diseases, and cardiomyopathies [4]. Tobacco and alcohol consumption, unhealthy lifestyle, and genetic factors are the most possible risk factors to develop CVDs. Similarly, elevated blood glucose levels, obesity, and high lipid levels contribute to secondary underlying risk factors contributing to the progression of CVDs [5]. Besides the apparent pathophysiology, a variety of clinical investigations predicted that tumor necrosis factor-alpha (TNF- $\alpha$ ) plays a key role in the pathogenesis of cardiac diseases. Cardiac 
monocytes and macrophages induce biochemical alterations along with compromised calcium metabolism. A decreased expression of $\beta$-adrenergic receptors, alterations in the natriuretic hormones, and increased matrix metalloproteinase (MMP) expression are also underlying risk factors [6].

Current treatment differs, depending on the risk and severity of CVDs. The main focus of all treatment protocols for CVDs is to improve the blood supply or prevent the pressure being exerted on cardiac walls in order to minimize tissue damage and capillaries rupture. Statin therapy is the most common option to dissolve the clots and regain endothelial membrane elasticity in blood vessels. Moreover, aspirin is the most frequently used drug for the secondary prevention of CVDs [7]. Alternatively, $\beta$-adrenergic receptor blockers are also prescribed as first-choice treatments for atrial fibrillation and coronary artery disease but they have been excluded from first-line therapy in the case of hypertension [8]. Angiotensin-converting enzyme (ACE) inhibitors and angiotensin-II receptor blockers (ARBs) are also prescribed for the treatment of hypertension, congestive heart failure, and myocardial infarction [9]. Apart from conventional renin-angiotensin antagonists, new candidates like sacubitril/valsartan (an angiotensin receptor-neprilysin inhibitor) were investigated as more promising drugs to reduce the mortality in patients with cardiac failure with low ejection fraction, but clinical trials are still ongoing [10]. On the other hand, severe and chronic cases need highly invasive interventions like coronary artery bypass grafts, percutaneous transluminal coronary angioplasty, and stenting [11].

Right now, the most frequently used CVD diagnostic methods include magnetic resonance imaging (MRI), X-ray computed tomography $(\mathrm{CT})$, electrocardiography (ECG), and echocardiography [12]. MRI employs radio waves to generate a 3D image of the heart and is most commonly used to diagnose stroke and atherosclerosis. CT uses X-rays beams to develop an image of the tissues with its high signal contrast. ECG records the electrical activity of the heart and monitors chest pain in patients with angina, heart attack, and arrhythmia. Echocardiography uses sound waves to create an image of the heart to detect cardiac disorders [13-16]. Additionally, advanced molecular imaging (MI) and cardiac immunoassays (CIAs) are new diagnostic methods to identify cardiac biomarkers (MMP-1, hepatocyte growth factor, cyclooxygenase 2, monocyte chemoattractant protein 1-MCP-1, tissue inhibitor of MMP-1). MI has been merged with various other techniques over the past to acquire more reliable and sensitive outcomes with accuracy $[17,18]$.

Despite ongoing progress in pharmacological and clinical treatment, CVDs are still the leading cause of morbidity and mortality worldwide. The current treatments are not disease-specific and generally lead to organ toxicity. The blood thinning agents and anti-coagulants may pose serious adverse effects to the heart and limit the optimal dose administration, which itself remains a serious therapeutic challenge [19]. Aspirin is reported to have an increased risk of bleeding, therefore, international guidelines on primary prevention of CVDs recommend aspirin only if the risk of cardiac events persist for at least 10 years [20]. Likewise, animal studies revealed that implantation of stents results in irritation, allergic reactions, and other significant issues like webbing, causing thrombogenicity [21]. The most commonly employed X-ray techniques have short imaging window and are limited in the contrast and differentiation of soft tissues, healthy tissues, and pathological tissues. Also, the diagnosis of CVDs using conventional techniques lacks precision, accuracy, and early diagnosis because of heterogeneity of CVDs [22,23].

Nanomedicine is a convergent discipline that combines the fields of biology, biochemistry, physics, engineering, genetics, and biotechnology to adjust the treatment and diagnosis of diseases [24-26]. Chronic heart diseases, especially myocardial infarction, eventually end up with a heart transplant, which may not be feasible, usually because of the unavailability of donors, autoimmune disorders, and chances of organ rejection. Recently, biomimetic materials based on nanotechnology gained increased attention for the development of scaffolds [27]. These scaffolds are composed of nanomaterials to provide mechanical, electromagnetic, and physical assistance in tissue repair and regeneration. They can provide cells via seeding at a site of injury or tissue deterioration to aid tissue functioning 
and healing [28]. Presently, nanopolymeric-coated biodegradable stents are being explored to resolve the issues with the conventional stents in use. These novel stents can improve drug release profiles along with a reduction in the platelet adhesion rate. Nanocomposite polymers including poly(lactic-co-glycolic acid) (PLGA), polycaprolactone (PCL), and polyhedral oligomeric silsesquioxane poly-(carbonate-urea) (POSS-PCU) are being used to construct anti-thrombogenic and blood compatible stents [29-31]. Nanomedicines of different characteristics and compositions are under extensive research for the treatment of CVDs. These include polymeric nanoparticles (NPs), silica-based nanoconjugates, micelles, liposomes, niosomes, exosomes, surface-modified nanostructures, nanofibers, nanotubes, metallic NPs, dendrimers, hybrid nanosystems, poly(ethylene glycol)-ated (PEGylated) nanospheres, and immunomodified nanoshells [32-36], as presented in Figure 1.

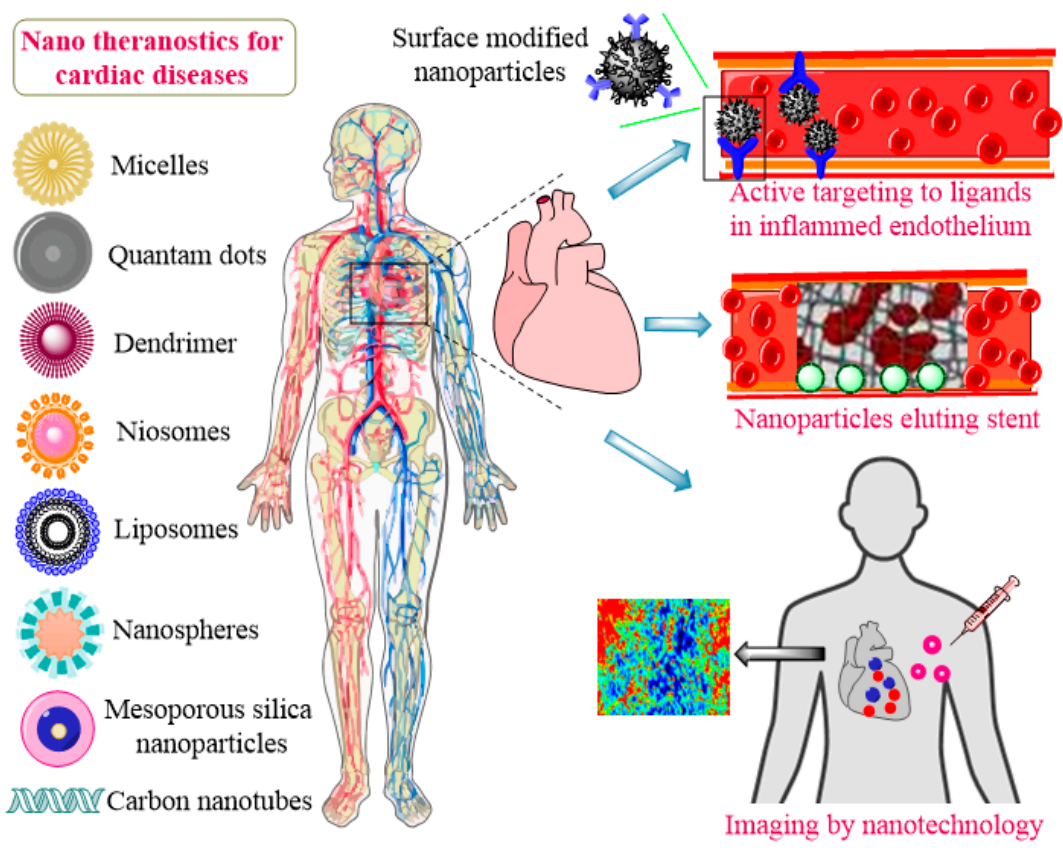

Figure 1. Application of nanotheranostics for CVDs.

CVDs may be treated if accurately diagnosed at early stages. Recent trends in nanotechnology also facilitated the diagnosis of CVDs. Nanoscale contrast agents emerged as multifaceted entities that can diagnose cardiac disorders in the very initial stages. Nanosensors are advantageous in contrast to conventional diagnostic approaches because they can incorporate a variety of imaging agents and simultaneously be used to load drugs for active targeting. They allow for a chelation of multivalent targeting moieties due to increased surface areas. Contrast-enhancing nanostructures for diagnosis and imaging comprise of fluorescent, paramagnetic, multimodal, light scattering, electron-dense, or radioactive particles, collectively termed as nanosensors [37,38]. Nanosensors provide clinical accuracy and usefulness by the detection of even single nucleotide polymorphisms (SNPs). Moreover, advancements in diagnosis and imaging using nanosensors further improved the detection of proteins and biomarkers in CVDs [39]. Nanosensors and nanomaterials allow for a local or targeted delivery and diagnosis, reduced sheer impact of blood flow, reduction in dose, and prolonged effects [40-42]. Disease-specific molecules or proteins can be targeted for treatment approaches by nanomaterials or quantitatively estimated by nanosensors, e.g., specific integrins $\left(\alpha_{v} \beta_{3}\right.$-integrin, vascular cell adhesion molecule 1-VCAM-1) expressed by atherosclerotic plaques can be exploited as target [43]. Emerging diagnostic tools like in vitro programmable bionanochips (lab-on-chip) are in demand for point-of-care testing [44]. Another advancement in the diagnosis of pressure-related diseases is the pressure biosensor. Such a biosensor uses self-oriented nanocrystals in spatial arrangements to capture micropressure changes on cardiovascular walls. These 
nanosensors hold optimistic results in the postoperative recrudescence of deep thrombus [45]. Moreover, various supraparamagnetic iron oxide NPs (SPIONs) and ultrasmall SPIONs (USPIONs) are showing promising results as contrast agents in clinical trials for CVDs. As macromolecules are unable to cross cellular biological barriers and have limited availability at diseased sites, targeted drug, and biologic delivery, along with diagnosis of the cardiac tissues and organelles which need to be further exploited for a rational treatment of CVDs.

In continuation of our groups' efforts related to the synthesis of nanomaterials and investigation of their potential bioapplications [26,46-62], we review here published data concerning the most well-known databases regarding different nanomaterial applicability for the diagnosis and treatment of CVDs. Critical points are highlighted in different sections/subsections of this manuscript, as follows below. This review provides 151 related references support the main aspects describing this topic.

\section{Diagnosis of CVDs}

\subsection{Potential Biomarkers of CVDs and Current Clinical Diagnosis Methods}

Nowadays, numerous techniques for the diagnosis of CVDs have been introduced, such as ECG, exercise stress test, cardiac immunoassay (CIA), and molecular imaging methods, as shown in Figure 2.

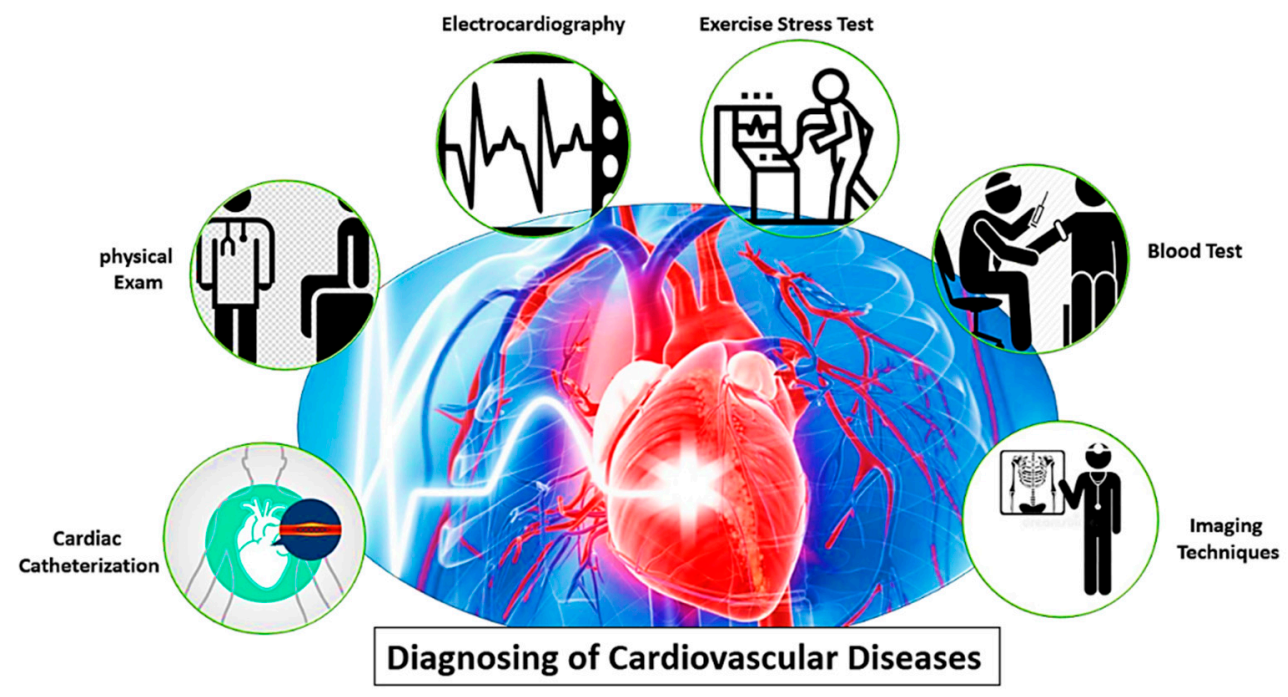

Figure 2. Current diagnosis techniques for CVDs.

For instance, because the levels of lipoproteins and lipids are well-established indicators of an unhealthy cardiovascular condition, cholesterol, high-density lipoprotein (HDL), and low-density lipoprotein (LDL) levels are often fully investigated by blood panels [63]. Other biomarkers related to CVDs include interleukin 6 (IL-6), C-reactive protein (CRP), MCP-1, fibrinogen (factor I), cardiac troponins I and T (cTnI and cTnT), B-type natriuretic peptides (BNP and NT-proBNP), D-dimer, and TNF- $\alpha$ [64-66]. Autoantibodies are also involved in the process of atherogenesis and were suggested as potential CVD biomarkers [67]. While various biomarkers have been explored and applied for the diagnosis of CVDs, conventional methods also involve expensive and time-consuming blood work analyses. Accurate and valid measures of risk and progression of CVDs are cardiac biomarkers found in human body fluids. They can be quantitatively estimated using different CIAs based on antigen-antibody immunoaffinity. In inflammatory conditions such as atherosclerosis, CRP is a marker molecule that is significantly increased. Cardiovascular morbidity is predicted by CRP levels and elevated CRP levels are associated directly with potential cardiovascular risks. The cTnI and cTnT markers are particularly important biomarkers for the diagnosis of acute $\mathrm{MI}$ and for the risk of stratification in acute coronary syndrome. Also, 
in both acute and chronic states, BNP and NT-proBNP are used as biomarkers to diagnose heart failure. D-dimer is a biomarker of thrombosis, acute aortic dissection, cardiovascular death, and ischemic heart disease [66]. Other non-invasive methods such as ECG may be used instead of relying on blood work to diagnose some symptoms such as arrhythmias which can be closely linked to cardiovascular problems [68].

One of the most commonly used methods for the imaging of multiple CVDs is the use of ultrasounds [69]. The positions of blood clots or irregular circulation may be detected by vascular ultrasounds and echocardiograms [70]. Methodologies such as coronary angiography (CA), MRI, CT, positron emission tomography (PET), and single-photon emission CT (SPECT) may be used for more comprehensive imaging to provide appropriate diagnostic details. Also, techniques such as PET-CT and SPECT-CT are constantly used in order to benefit from several modalities at once [71]. While significant advances in CVD imaging have been made, patients still often need to be given massive amounts of contrast agents, and reports are often misunderstood which can result in a wrong diagnosis [72,73].

\subsection{Nanoparticles for the Early Diagnosis of CVDs}

In many countries, CVDs are the primary cause of death and accounts for around one-third of all deaths in the world [74]. More effective diagnostics and safe, non-invasive imaging methods are critically needed for use as diagnostic methods to provide detailed information over time about CVDs. Nanotechnology includes structures with nanoscale dimensions, having unique physicochemical properties that render them desirable to improve the current diagnosis methods. Due to their peculiar optical property, electrical property, and excellent biocompatibility, nanomaterials have been extensively applied to CIAs, including electrochemiluminescence (ECL), electrochemistry (EC), and photoelectrochemistry (PEC). All established sensors used in the diagnosis of CVDs are presented in the following paragraphs [75].

Due to their small size, high flexibility, and low cost, field effect transistor-based (FET) sensors have been used in biomedical research [76]. For the identification of cTnT in the field effect transistor (FET) system, Surya et al. [77] used a blend of $\mathrm{Co}_{3} \mathrm{O}_{4}$ and $\mathrm{AuNPs}$. By adsorbing its complement biotinylated DNA aptamer on the channel surface, they achieved cardiac troponin $\mathrm{T}$ identification. Using this unit, analyses indicated a $250 \%$ increase in responsiveness and a detection limit of $0.1 \mu \mathrm{g} / \mathrm{mL}$.

Due to its high sensitivity and rapid re-response time, EC attracted considerable attention, becoming one of the most promising techniques for diagnosis. In addition, due to their catalytic properties, conductivity, binding affinity, and large surface area, nanomaterials are highly valuable to improve the sensitivity and strength of EC [78]. Many forms of CVD nanosensors include electrochemical impedance where electrode changes induced by charged antigen interactions are reported [79]. For instance, Wang et al. [80] reported an electrochemical impedance spectroscopy (EIS) sensor system (label-free) for extremely sensitive cTnI detection using a modified glass carbon electrode (GCE) AuNPs as a base electrode. The molecular recognition probe was a special peptide (CFYSHSFHENWPS). The charge transfer resistance (Rct) of the biosensor at the time of cTnI binding was logarithmically directly proportionate to the cTnI concentration in the range of $15.5 \mathrm{pg} / \mathrm{mL}$ to $1.55 \mathrm{ng} / \mathrm{mL}$ with a detection limit of $3.4 \mathrm{pg} / \mathrm{mL}$. In another study, an apta sensor for $\mathrm{cMb}$ identification using polyethylene imine (PEI) functionalized thin films of reduced graphene oxide was introduced by Sharma et al. [81]. Acute myocardial infarction (AMI), also known as "heart attack", is one of the world's leading causes of death and an important cardiac biomarker_cardiac myoglobin ( $\mathrm{cMb}$ ) — can be used for early AMI diagnosis [82]. As a reducing agent for graphene oxide, PEI, a cationic polymer, was used to provide largely positive charges on the rGO surface and to enable direct adsorption of negatively-charged single-strand DNA aptamers against $\mathrm{cMb}$ through electrostatic attraction without any chemical ligand or linking. Through differential pulse voltammetry, the existence of $\mathrm{cMb}$ was identified on $\mathrm{Mb}$ aptamer-modified electrodes by assessing the actual shift due to direct electron transfer between $\mathrm{cMb}$ proteins $\left(\mathrm{Fe}^{3+} / \mathrm{Fe}^{2+}\right)$ and electrodes. Detection limits were 
of $0.97 \mathrm{pg} / \mathrm{mL}$ (phosphate-buffered saline) and $2.1 \mathrm{pg} / \mathrm{mL}$ (10-fold-dilute human serum), with a logarithmic $\mathrm{cMb}$ concentration linear nature. In a similar study, by developing aptamer sensors for BNP-32 and cTnI, Grabowska et al. [83] reported a systematic method to multianalyte nanostructured materials for cardiac biomarkers. In patients with systemic left ventricular (LV) dysfunction, BNP-32 serves as a possible biomarker of elevated left ventricular-diastolic strain. Also, in AMI patients, an increased level of this protein was seen [84]. For this purpose, with PEI/reduced graphene oxide films, commercial goldbased screen-printed electrodes have been modified electrophoretically. The established sensor had a linear relation in the case of BNP-32 from $1 \mathrm{pg} / \mathrm{mL}$ to $1 \mu \mathrm{g} / \mathrm{mL}$ in serum and linearity was observed for $\mathrm{cTnI}$ from $1 \mathrm{pg} / \mathrm{mL}$ to $10 \mathrm{ng} / \mathrm{mL}$ as needed for an early monitoring of CVDs.

Together with fluorescent assays, immunoassays are by far dominant analytical approaches because of their outstanding flexibility and signal enhancement capability. The performance of fluorescence assays has been used with nanomaterials because nanomaterials have a good solubility, low toxicity, and strong binding affinity of biomolecules that can be coupled with various intensive fluorescence amplification materials [85]. A robust nanozyme-linked immunosorbent assay based on graphitic carbon nitride quantum dots ( $\mathrm{g}-\mathrm{C}_{3} \mathrm{~N}_{4}$ QDs) has been reported by Miao et al. [86], achieving ratiometric fluorescent and colorimetric dual-modal sensing performance. Detection of cTnI was performed as a proof-of-study demonstration. In another study, Gogoi et al. [87] developed a responsive detection method in the biological fluid (serum) and buffer for cTnT using a nanoplatform based on molybdenum disulfide $\left(\mathrm{MoS}_{2}\right)$ and NIR-active fluorescent anti-cTnT-labelled carbon dots. In the range of concentrations of $0.1-50 \mathrm{ng} / \mathrm{mL}$ with a detection limit of $0.12 \mathrm{ng} / \mathrm{mL}$ and a quantification limit of $0.38 \mathrm{ng} / \mathrm{mL}$, a linear behavior was found between the concentration of cTnT and the intensity of fluorescence. Results of the analysis showed that the nanosensor has a coefficient of co-relation of 0.99 .

ECL includes electron-transfer reactions that produce excited states and light emissions. ECL may act as a common diagnostic assay to quantify biomarker expression levels because the observed emission intensity in ECL is proportional to the biomarker concentration. Luminol is one of the most important ECL signal enhancers but it displays a weak signal and low solubility. Because of their large specific surface area, ability to functionalize signal amplification materials, conductivity, and surface charge, luminol-functionalized nanomaterials can address the limitations of conventional luminol and greatly increase strength and sensitivity [88]. Dong et al. [89] developed a novel sandwich-style ECL immunoassay to detect NT-proBNP. The method focused on ECL resonance energy transfer (RET) between silver nanocubes covered as the donor by semicarbazide-modified gold NPs (AgNC-sem@AuNPs) and the acceptor is a Ti(IV)-based metal-organic structure of type MIL-125. The assay operated in a concentration range of $0.25 \mathrm{pg} / \mathrm{mL}$ to $100 \mathrm{ng} / \mathrm{mL}$ with a low detection limit of $0.11 \mathrm{pg} / \mathrm{mL}$ at $\mathrm{S} / \mathrm{N}=3$.

Biosensor surface plasmon resonance (SPR) measures changes in the refractive index on the surface of a sensor. Nanomaterials have amplified signals with plasmonic and optical properties, good distribution capacity, and high photostability, thereby enhancing SPR sensitivity [90]. Immunomagnetic separation technology-assisted SPR biosensing was reported by Chen et al. [91] for human cTnI. The platforms for immobilizing capture antibody $(\mathrm{cAb})$ and SPR sensing were used as Au films modified by Au NPs and polydopamine (PDA). The magnetic immune probe was prepared by adding the detection antibody $(\mathrm{dAb})$ to the surface of PDA-coated $\mathrm{Fe}_{3} \mathrm{O}_{4}$ NPs for precise capture, magnetic separation, and target analyte enrichment (cTnI) from the samples. The detection limit of cTnI was $3.75 \mathrm{ng} / \mathrm{mL}$, i.e., 320-fold lower than achieved by a sensing strategy based on PDA.

Enzyme-linked immunosorbent assay (ELISA) is a commercialized approach that uses an enzyme-linked conjugate and enzyme substrate to monitor the concentrations of targets via color change of antigen-antibody reactions. The efficiency of the ELISA and below lateral flow assay significantly improved the specific physical properties and 
biocompatibility of nanomaterials (LFA) [92]. A new type of multimodal ELISA (M-ELISA) based on Au@Pt nanodendrites' specific properties was developed by Jiao et al. [93], with good quality for the clinical diagnosis for serum samples.

PEC is a valuable screening method since the biological interactions between biomarkers and corresponding recognitions cause a photocurrent shift. PEC sensitivity can be enhanced by nanomaterials due to their low background signal [94]. The split-type liposomal PEC immunoassay system consisting of sandwich immunorecognition, CdS QDs-loaded liposomes (QDLL), and separate $\mathrm{TiO}_{2}$ nanotube electrode release and subsequent capture of QDs was stated by Xue et al. [95]. The proposed method, with cTnI as a goal, achieved an efficient activation of the $\mathrm{TiO}_{2}$ nanotube electrode leading to the generation of a signal in the split-type PEC immunoassay.

Due to their excellent multiplexing performance, high sensitivity, and wide dynamic range, surface-enhanced Raman scattering (SERS) immunoassays show a strong potential for clinical CVD diagnosis. The preparation and attachment of Raman labels was simplified by nanomaterials, thus improving sensitivity [96]. A new signal enhancement SERS platform for cTnI recognition and detection using AuNPs, graphene oxide (GO), and magnetic beads was documented by Fu et al. [97]. cTnI with a good detection limit of $5 \mathrm{pg} / \mathrm{mL}$ was selectively detected by the proposed SERS-based immunoassay and a good linearity was obtained in the range of $0.01-1,000 \mathrm{ng} / \mathrm{mL}$. Table 1 summarizes the description of such nanostructures in the diagnosis of CVDs.

Table 1. Summary of some nanostructures in diagnosis of CVDs.

\begin{tabular}{|c|c|c|c|c|}
\hline Detection Methods & Nanostructures & Limit of Detection & Biomarkers & Refs. \\
\hline Field effect transistor-based (FET) & $\mathrm{Co}_{3} \mathrm{O}_{4}, \mathrm{AuNPs}$ & $0.1 \mu \mathrm{g} / \mathrm{mL}$ & $\begin{array}{l}\text { cardiac troponin-I } \\
(\mathrm{cTnI})\end{array}$ & [77] \\
\hline Electrochemistry (EC) & reduced graphene oxide & $0.97 \mathrm{pg} / \mathrm{mL}$ & $\begin{array}{l}\text { cardiac myoglobin } \\
(\mathrm{cMb})\end{array}$ & [82] \\
\hline Fluorescence immunoassay & $\begin{array}{l}\text { molybdenum disulfide } \\
\left(\mathrm{MoS}_{2}\right) \text {, carbon dots }\end{array}$ & $0.12 \mathrm{ng} / \mathrm{mL}$ & cTnI & [87] \\
\hline Electrochemiluminescence (ECL) & $\begin{array}{l}\text { semicarba-zide-modified } \\
\text { AuNPs, AgNPs, MOFs }\end{array}$ & $0.11 \mathrm{pg} / \mathrm{mL}$ & $\begin{array}{l}\text { N-terminal pro-B-type } \\
\text { natriuretic peptide } \\
(\mathrm{NT} \text {-proBNP) }\end{array}$ & [89] \\
\hline Surface plasmon resonance (SPR) & $\mathrm{AuNPs}, \mathrm{Fe}_{3} \mathrm{O}_{4} \mathrm{NPs}$ & $3.75 \mathrm{ng} / \mathrm{mL}$ & cTnI & [91] \\
\hline $\begin{array}{l}\text { Enzyme-linked immunosorbent } \\
\text { assay (ELISA) }\end{array}$ & Au@Pt nanodendrites & $0.34 \mathrm{ng} / \mathrm{mL}$ & cTnI & [93] \\
\hline Photoelectrochemistry (PEC) & $\begin{array}{l}\text { CdS quantum dots (QDs), } \\
\mathrm{TiO}_{2} \text { nanotubes }\end{array}$ & $0.5 \mathrm{pg} / \mathrm{mL}$ & cTnI & [95] \\
\hline $\begin{array}{l}\text { Surface-enhanced Raman } \\
\text { scattering (SERS) }\end{array}$ & $\begin{array}{l}\text { AuNPs, graphene oxide } \\
\text { (GO), magnetic beads } \\
\text { (MB) }\end{array}$ & $5 \mathrm{pg} / \mathrm{mL}$ & cTnI & [97] \\
\hline
\end{tabular}

\subsection{Nanostructures for CVD Imaging}

Due to their improved resolution, signal amplification, and simple manipulation, nanomaterials with good bioavailability and flexibility improved the precision and specificity of clinical imaging applications. NPs are ideal for imaging, among other nanomaterials, because of their mobility in both internal and external vascular systems, high surface area to volume ratio, and imaging versatility. These benefits enable them to circulate across low-restricted human bodies and produce functional imaging vehicles as contrast agents when applied in imaging environments, resulting in dramatically improved diagnostic performance [98]. Due to their stability, NPs can be used for RNA detection in intravascular systems. NPs that are injected or ingested and functionalized with detectable molecules can circulate through the human body and target specific RNA for diagnosis. However, 
because RNA detection involves NPs entering and interacting with cells, the size, shape, morphology, and density of functionalized NPs has to be carefully investigated. In addition, by integrating materials such as photoacoustic, fluorescent, radioactive, paramagnetic, superparamagnetic, electron-dense, light-scattering particles, and multimodal functional groups that are observable by imaging, NPs can serve as nanoscale contrast agents [99-101].

Historically, imaging technology has mainly been established for cancer-related applications using AuNPs. AuNPs have successfully been employed in the cardiovascular area utilizing their desirable bioactivity and flexibility [102]. Photoacoustic imaging in which AuNPs can be engaged depend on the thermal changes of nanoagents or tissues when pulsed laser beams are absorbed [103].

A photoacoustic molecular probe based on Au nanoshell targeting VCAM-1 in mice was described by Rouleau et al. [104,105]. Molecular targets may be caused by infections, apoptosis or calcification in the form of CVDs. VCAM-1 is mainly expressed at low levels and its upregulation is a significant marker of chronic inflammation in hearts during the formation of atherosclerotic plaque [104,105]. Ex vivo optical projection microscopy of atherogenic and control mice of the heart and aortas verified the preferential aggregation of nanosensor in atherosclerotic-prone regions in mice, thus verifying the usefulness of the in vivo technique in small animals for clinical studies [104]. In order to provide improved evaluations of atherosclerotic plaque, propidium iodide (sonoporation tracer) can also be paired with ultrasound imaging technology.

Optical coherence tomography (OCT) is another method for cardiovascular imaging using AuNPs. In this methodology, the infrared signal is guided to the target tissue from a broadband coherent light source and an image is built based on the back-scattered light [106,107]. Hu et al. [108] for instance, showed that individual cells suspended in biocompatible fluids may be identified using cardiovascular OCT. Pertinently, the integration of Au nanoshells as intracellular contrast agents with this catheter-based clinical methodology led to a significant increase in the reflected signal generated by individual cells.

MRI is a non-invasive approach that can provide comprehensive vasculature data that is important for the efficient CVD diagnosis [109]. Gd is often used in MRI to produce a positive signal due to its high paramagnetic potential as a T1-weighted contrast agent [110]. SPIONs have also been commonly used as MRI contrast agents [111]. Iron oxide NPs act as T2-weighted contrast agents that produce negative signals, unlike Gd which is a T1 contrast agent. Twin-modal frameworks have been suggested in order to acquire the effects of both $\mathrm{T} 1$ and T2 contrast agents. In this context, Qin et al. [112] stated that uniformly distributed $\mathrm{Fe}_{3} \mathrm{O}_{4} / \mathrm{Gd}_{2} \mathrm{O}_{3}$ core@shell NPs were rationally designed and produced successfully for T1T2 dual-mode contrast agents. For improved hydrophilia and bioactivity, the $\mathrm{Fe}_{3} \mathrm{O}_{4} / \mathrm{Gd}_{2} \mathrm{O}_{3}$ core@shell NPs have been coated with nontoxic 3,4-dihydroxyhydrocinnamic acid (DHCA). T1- and T2-weighted imaging photographs in vivo indicated that FGDA nanocubes have the potential to improve MRI as a dual-mode contrast agent. Figure 3 shows diagnosis methods of CVDs including biomarker detection and bioimaging techniques within the nanotechnology platforms. 


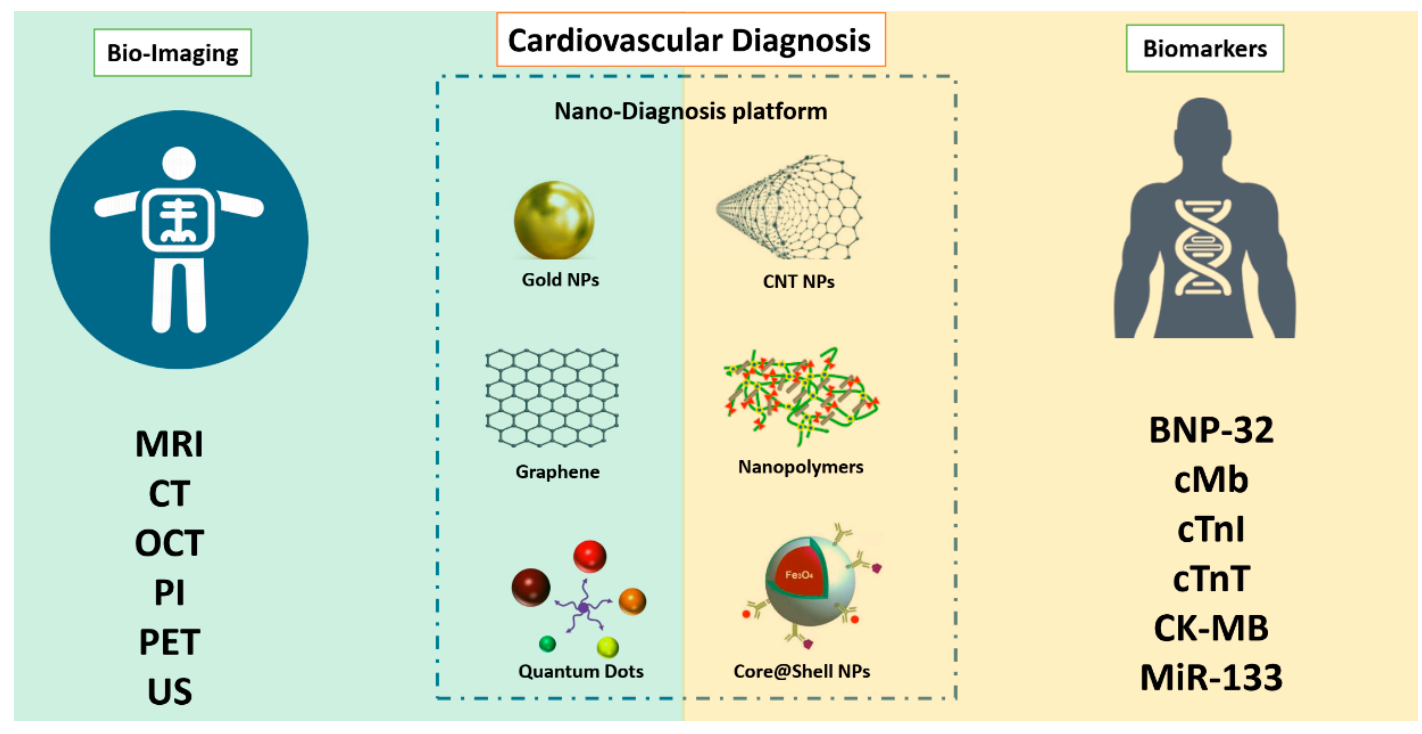

Figure 3. Diagnosis methods for CVDs.

\section{Applications of Nanomaterials in the Treatment of CVDs}

Nanomaterials also play significant roles in the treatment of CVDs [113]. Nanomaterial applications are closely related to the medical research, providing strong alternatives for CVDs. Many new strategies may enhance the efficacy of these treatments. Progress has been made in the past decades in the application of nanotechnology and nanomaterials for CVDs [114-124]. NPs are considered as safe and efficacious platforms for different drugs whose clinical utilities are limited due to their toxicity or unfavorable pharmacokinetic properties. Table 2 and Figure 4 presents common nanomaterials used in CVD application and their common features [40].

Table 2. Category and features of nanodrug carriers for the treatment of CVDs.

\begin{tabular}{|c|c|c|c|c|c|}
\hline Type & Structures & $\begin{array}{l}\text { Methods of Drug } \\
\text { Loading }\end{array}$ & Advantages & Limitations & Refs. \\
\hline Liposomes & lipid bilayers & $\begin{array}{l}\text { chemical/physical } \\
\text { encapsulation }\end{array}$ & $\begin{array}{c}\text { non-toxic, } \\
\text { biocompatible, } \\
\text { non-immunogenic }\end{array}$ & $\begin{array}{l}\text { low stability, } \\
\text { leakage }\end{array}$ & {$[19,125]$} \\
\hline Polymeric NPs & $\begin{array}{c}\text { nanospheres, } \\
\text { nanocapsules/polymer- } \\
\text { based NPs with } \\
\text { lipophilic core }\end{array}$ & $\begin{array}{c}\text { chemical/physical } \\
\text { encapsulation }\end{array}$ & no leakage, stable & systemic toxicity & {$[126,127]$} \\
\hline $\begin{array}{c}\text { Metal } \\
\text { nanomaterials }\end{array}$ & $\begin{array}{l}\text { NPs, nanorods, } \\
\text { nanowire }\end{array}$ & $\begin{array}{c}\text { physical } \\
\text { encapsulation }\end{array}$ & $\begin{array}{c}\text { magneto-optical } \\
\text { response } \\
\text { characteristics and } \\
\text { antibacterial property }\end{array}$ & $\begin{array}{l}\text { toxicity, hard to } \\
\text { degrade }\end{array}$ & [128] \\
\hline $\begin{array}{l}\text { Polymeric } \\
\text { micelles }\end{array}$ & $\begin{array}{l}\text { core shell structure } \\
\text { formed by } \\
\text { self-assembly }\end{array}$ & $\begin{array}{l}\text { chemical/physical } \\
\text { encapsulation }\end{array}$ & $\begin{array}{l}\text { easy preparation, } \\
\text { highly stable }\end{array}$ & $\begin{array}{l}\text { low stability, } \\
\text { depolymerization } \\
\text { after dilution }\end{array}$ & [129] \\
\hline $\begin{array}{c}\text { Inorganic } \\
\text { non-metallic } \\
\text { nanomaterials }\end{array}$ & $\begin{array}{l}\text { same size with } \\
\text { adjustable pore size }\end{array}$ & $\begin{array}{c}\text { physical } \\
\text { encapsulation }\end{array}$ & $\begin{array}{c}\text { large surface area, } \\
\text { stable size, high drug } \\
\text { loading }\end{array}$ & $\begin{array}{c}\text { low rate of } \\
\text { biodegradation }\end{array}$ & {$[130,131]$} \\
\hline
\end{tabular}






Figure 4. Nanoparticle-mediated drug delivery systems to target CVDs. The systems include magnetic and AuNPs, self-assembling micelles, liposomes, carbon nanotubes, quantum dots, and polymeric NPs formed via assembly of polymers containing therapeutic agents.

\subsection{Liposomes}

There is much interest in developing lipid-based drug delivery systems such as solid lipid NPs, liposomes, and self-emulsifying systems to target CVDs. The studies demonstrated that drugs encapsulated in liposomes or in lipid nanocarrier systems can lower the toxicity issues compared with free drug intervention in CVDs. Lipid-based systems have been explored to deliver biomolecules for vascular abnormalities [132].

Dzau and coworkers [133] showed the efficacy of fusigenic lipids for gene therapy of CVDs. Another study encapsulated DNA in liposomes with an average diameter of $200 \mathrm{~nm}$ where the lipid membrane was modified with proteins of UV-inactivated hemagglutinating virus [134]. The liposomes attached to plasma membranes within a short time, allowing for cytostatic gene therapy in models of vascular proliferative diseases. Electrostatic DNA complex with cationic liposomes has also been explored for vascular disease gene therapy. In some studies, antibodies attached to liposomes were utilized to actively target fibrinogen, intercellular adhesion molecule-1, and fibrin. This type of liposomes provides a method for the use of ultrasound-induced cavitation to transport fibrinolytic agent. Dasa and coworkers $[135,136]$ developed peptide liposomal systems with an affinity for cell types present in postmyocardium infarction. They encapsulated the poly(ADP ribose) polymerase-1 inhibitor AZ7379 in a liposomal system and measured increased bioavailability of AZ7379 at infarct zone $24 \mathrm{~h}$ after injection compared with non-liposomal AZ7379. Lestini et al. [137] functionalized liposomes using arginine-glycine-aspartic acid (RGD) to target integrin GPIIb-IIIa receptors on activated platelets. Moreover, surfactant oil godextran incorporation in the liposomes provided knowledge into the effects of vesicle perturbation on liposome clearance. This ligand-gated delivery of liposomes highlights the importance of selective targeting in design of effective targeted delivery system in CVD treatment. van der Valk et al. [138] manipulated liposome-based drug delivery to improve the risk/benefit ratios of active agents to target atherosclerotic plaques as the very 1st clinical study of prednisolone-loaded liposomes (PLPs) against atherosclerosis. When tested in humans, PLPs build on pharmacokinetic profiles with increased plasma half-life of $63 \mathrm{~h}$. Moreover, intravenously infused liposomal NP PLPs (LN-PLPs) appeared in 75\% of 
the macrophages. The study data concluded on the successful delivery of long circulating liposomes to atherosclerotic plaque macrophages in patients, showing the value of the approach for the development and imaging-assisted evaluation of future nanomedicines in atherosclerosis [138]. Laing et al. [139] evaluated the thrombolytic effects of tissue plasminogen activator (tPA) encapsulated in echogenic liposomes (ELIPs) in an in vivo rabbit aorta clot model. Thrombus was studied in the abdominal aorta and the etiology was imaged before ELIP administration while blood flow velocities were measured before and after treatment. Ultrasound treatment enhanced the thrombolytic effect of tPA-loaded ELIPs with complete recanalization rates versus ineffective empty ELIPs, highlighting the effective thrombolytic effects of tPA in vivo via ELIP loading, while Doppler treatment increased the thrombolytic effects with enhanced and rapid recanalization rates. Zhong et al. [140] manipulated the bioactive flavonoid substance breviscapine obtained from traditional Chinese medicine against CVDs. This study used multivesicular liposomes (MVLs) as sustained release system to reduce the frequency of injection and afford patient compliance. Pharmacokinetics study were performed using MVLs containing breviscapine relative to traditional liposomes upon intramuscular injection in rats. The results showed increased residence time and drug release in vitro while absorption in vivo showed good linear correlation, supporting the concept of using MVLs as a sustained delivery system of breviscapine for CVDs. Huang et al. [141] worked on an injectable delivery system that can selectively drive thrombolytics to sites of active platelet aggregation, having significant potential for vascular occlusion therapy. The authors performed surface modification with a conformationally high affinity RGD motif for GPIIb-IIIa-binding. The targeting/binding of RGD-modified liposomes was studied by scanning electron microscopy, fluorescence, and flow cytometry and the attachment of the RGD liposomes was evaluated in a rat model and monitored ex vivo by fluorescence microscopy. The results revealed the feasibility of changing the binding potential of vascularly targeted liposomes and platelet targeting using surface-modifying ligands. Figure 5 presents functionalized liposomes for targeting the CVDs.



Figure 5. Functionalized liposomes with targeting ligands (PEG, antibodie, apartmers, proteins, carbohydrates).

\subsection{Polymeric Nanoparticles}

The tunable properties of polymeric NPs are the main focus of CVD treatment, having a potential for reabsorption in the body. Polymeric NPs can be coupled or free floating with another material [142].

Research was performed to immobilize PLGA on a polytetrafluoroethylene film as a material to develop vascular grafts [143]. This approach may be used to deliver specific 
molecules such as antithrombotic drugs to act against the regular side effects of thrombosis. Ahadian et al. [144] developed polymeric nanomaterials for CVD applications using a matrix of polyester and carbon nanotubes (CNTs) with enhanced electrical conductivity and stability, allowing to stimulate cell-cell coupling. Matoba et al. [135] investigated polymeric PLGA NPs as a nanodrug delivery system to impact monocyte-derived inflammation during atherosclerosis. FTIC-loaded PLGA NPs were incorporated in mice after $2 \mathrm{~h}$ of plaque rupture, as noted by flow cytometric analysis of aortic and peripheral leukocytes, with delivery of FITC NPs to peripheral monocytes and next to aortic macrophages 7 days after injection. This group also developed PLGA NPs encapsulated with pioglitazone, a clinically approved thiazolidinedione that activates the peroxisome proliferator activated receptor-gamma (PPAR $\gamma)$, allowing to regulate inflammation in mice in vivo for up to 4 weeks. Pioglitazone NPs significantly reduced the number of fibrous caps and enhanced the fibrous cap thickness, but orally administered pioglitazone did not affect the number of fibrous caps thickness or plaque area, showing the efficacy of PLGA NPs as delivery system. Figure 6 presents nanodrug delivery systems mediated treatment for acute coronary syndrome.

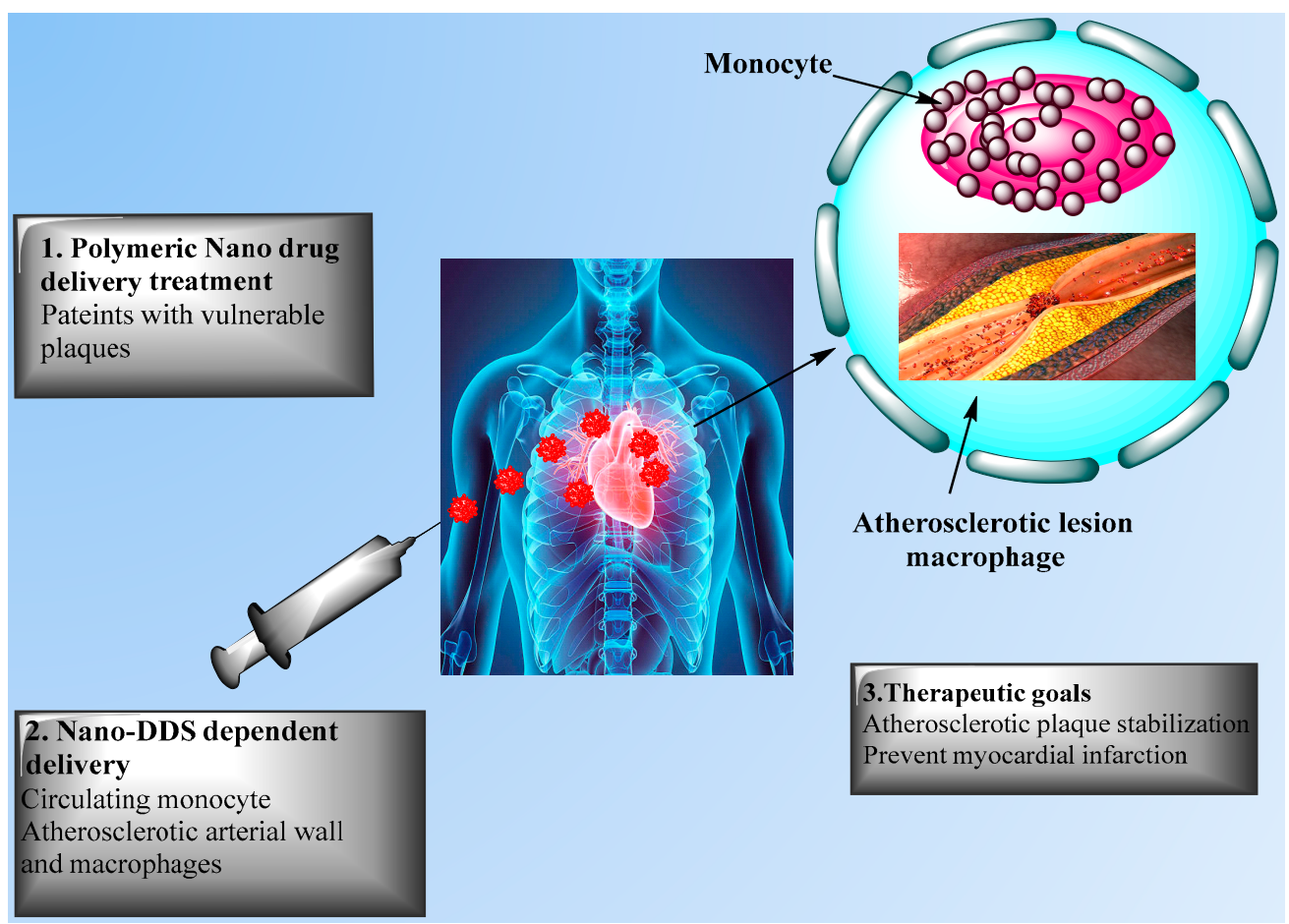

Figure 6. Nanodrug delivery systems for the treatment of acute coronary syndrome. The Figure presents nanodrug delivery system (Nano-DDS)-mediated treatments for patients with unstable plaque via (1) intravenous injection and (2) delivery to circulating monocytes, with (3) therapeutic goals including atherosclerotic plaque stabilization and prevention of acute myocardial infarction.

\subsection{Micelles}

Micelles are specialized, efficient carriers for poorly soluble drugs as nanodimensional colloidal particles with a hydrophilic shell and hydrophobic core. Surface-modified polymeric micelles primarily consist of amphiphilic macromolecules and have many applications in the areas of drug delivery and theranostics.

Various polysaccharides have been employed to prepare polymeric micelles. PEGylated polycationic block copolymeric micellar assembly was established to target vascular injury in the rabbit carotid artery for gene delivery [145]. Peters et al. [146] demonstrated that a PEG-based lipid micelle system co-encapsulated with a fluorophore as an imaging agent was capable of delivering an anticoagulant drug at the similar targeting site. 
Other studies demonstrated the efficacy of PEG-based lipid micelles with surface-modified scavenger receptor-based antibodies and encapsulated with gadolinium (Gd) complex to particularly accumulate in atherosclerotic arterial sites. At atherosclerotic aortic sites, Gdencapsulated micelles functionalized with anti-CD36 antibodies could reveal macrophages in human atherosclerotic aortic tissues obtained at autopsy. Ding and colleagues $[147,148]$ explored a number of probable micelle-based strategies intended for improperly functioning endothelia that forms a significant part of thrombotic or atherosclerotic tissues. Their results showed a significant potential of micellar site-specific delivery and usefulness for the treatment of CVDs. Wennink et al. [145] worked on the targeted elimination of macrophages by photodynamic therapy as a promising approach to reduce atherosclerotic plaques. Temoporfin or m-tetra(hydroxyphenyl)chlorin (mTHPC) may be suitable as photosensitizer for application in atherosclerotic lesions and cancer. In this particular study, mTHPC was loaded in polymeric micelles developed by the film hydration method using benzyl-PCL-b-methoxy PEG. The authors reported that delivery of mTHPC in blood plasma from the micelles occurred after $30 \mathrm{~min}$ and that accumulation of mTHPC in atherosclerotic lesions of mice resulted in binding to lipoproteins upon release from the micelles. Future experiments may allow to increase the stability and accumulation of THPCloaded Ben-PCL-mPEG micelles to macrophages of atherosclerotic lesions. Yoo et al. [149] developed fibrin-binding, peptide amphiphile micelles (PAMs) by encapsulation the targeting peptide cysteine-arginine-glutamic acid lysine alanine (CREKA) with two types of amphiphilic molecules containing $\mathrm{Gd}$, the chelator diethylenetriaminepentaacetic acid (DTPA) as DTPA-bis(stearyl amide) and 1,2-distearoyl-sn-glycero-3-phosphoethanolamineN-(PEG)-2000)-DTPA as (DSPE-PEG2000-DTPA). An atherosclerotic mouse model was evaluated for clot-binding properties in vitro, contrast enhancement, and safety via magnetic and optical imaging. The results of in vivo imaging and optical studies of the aortas and heart showed the fibrin specificity conferred by the peptide ligand. Biodistribution studies confirmed that all micelles were cleared via renal clearance and the reticuloendothelial system. These studies revealed the successful molecular imaging in vitro vs. in vivo for site-specificity and provided a platform for the detection of thrombosis via contrast-enhancing agents in theranostic applications. Kirana et al. [150] evaluated the efficacy of artificially developed micelles using naturally developed micelles from pig bile to assess the potential of inhibitors targeting cholesterol uptake in cultured Caco-2 cells. Overall, pig bile was a convenient and cost-effective source of micelles for cellular uptake and cholesterol micelle solubility assays that was also efficient to screen potential cholesterol lowering agents.

\subsection{Magnetic Nanoparticles}

During the last decades, magnetic NPs have been used at large scale in biomedical applications, including as contrast agents in immunoassays, MRI, and cell sorting assays. Among them, iron oxide-based magnetic NPs are most commonly employed due to their lesser saturation magnetization, lower magnetic characteristics, and lower specific loss of power compared with cobalt $(\mathrm{Co})$ iron $(\mathrm{Fe})$ nanomaterials. NPs such as perfluorocarbon NPs and super magnetic NPs have been developed for MRI. These particles designed to target specific receptors or epitopes in tissues are near to enter clinical trials for CVD applications. As angiogenesis is the key part of atherosclerotic plaques, specific recognition of angiogenesis in early vascular diseases is not possible. However, paramagnetic NPs can spatially locate and measure atherosclerotic plaques in hyperlipidemic rabbits $[151,152]$. In this study atherosclerotic rabbits were treated with $\alpha_{\mathrm{v}} \beta_{3}$-targeted paramagnetic NPs including fumagillin and MRI signal assessments of neovascular proliferation within the aortic wall. Magnetic NPs have physical and biological properties with desirable size distribution, higher magnetic flux density with increasing penetrability, and an ability to translate magnetic waves to heat energy, being both highly biocompatible and non-toxic. SPIONs are among most used magnetic NPs and can serves as good nanotheranostics [153]. In biomedical applications, magnetic NPs are template particles (micelles, perfluorocarbon 
bubbles, lipid vesicles etc.) that may be modified with paramagnetic elements such as chelated Gd or particles of metals with greater magnetization such as iron and cobalt. In angiogenesis, integrin $\mathrm{v} 3$ is upregulated in the vascular endothelium, leading to the development of functionalized magnetic NPs with v3-targeting ligands decorated with $\mathrm{Gd}$ and the potential use of contrast-enhanced MRI for CVDs associated with angiogenic vasculature $[154,155]$.

\subsection{Gold Nanoparticles}

AuNPs provide suitable carrier systems in the field of nanotechnology, especially to treat CVDs, due to their properties such as low cytotoxicity, stability, and biocompatibility. They have a broad level of applications in biomedical science including molecular labeling and drug delivery, with a significant stability in the circulatory system and ability to decompose in a proper environment once reaching the target site. The large surface area property of AuNPs allows their functionalization with a number of biological molecules (ligands) including drugs, proteins, antibodies, and genes.

Work is ongoing for the imaging of CVDs based on the use of AuNPs with applications in atherosclerotic lesions and inflammation [156]. Photothermal therapeutic strategies have been also developed using the properties of $\mathrm{Au}$ for the preparation of vascular drugencapsulated nanostructures. The following reaction can assist in thermal instability of NPs to liberate the encapsulated drugs at the respective targeting site. Researchers are working to evaluate the role of macrophages in vascular lesions and their ability to uptake AuNPs to facilitate contrasting enhanced intravascular photoimaging of cardiovascular abnormalities. Moreover, AuNPs have also efficient antioxidant properties that may be usefult to manage CVDs. The photothermal property of AuNPs was employed for plaque specific delivery of such NPs for the diagnosis of photothermal revascularization of blocked arteries [157]. Ghann and coworkers [158] encapsulated lisinopril as an active agent to develop AuNP-based CT contrast agents. AuNP conjugated with pure lisinopril, reduced thioctic lisinopril, or thioctic lisinopril were developed through ligand exchange reaction on citrate-coated AuNPs. The higher stability properties of thioctic lisinopril AuNPs were used to evaluate the targeting of angiotensin converting enzyme (ACE) using X-ray CT. The images showed high contrast in the region of heart and lungs clearly indicating the targeting of $\mathrm{ACE}$ and overexpression of $\mathrm{ACE}$ was related to the development of pulmonary and cardiac fibrosis. This new strategy may serve as a useful tool to monitor cardiovascular pathophysiology using CT imaging. AuNPs used alone or in combination may offer large scale treatment and diagnosis approaches in CVDs.

\subsection{Dendrimer Nanostructures}

Dendrimer nanostructures exhibit tree-like architectures occurring via either the convergent method or divergent method. Polyamido-amines are most common dendrimers with nitric oxide (NO) as free radical for application in CVDs due to its prominent relaxing action on vascular smooth muscle $[159,160]$. siRNA-based oligo-arginine conjugated dendritic delivery systems were used to silence ATIR expression in cardiomyocytes in vitro, showing efficient storage of cardiac functions in case of ischemic reperfusion injury in rats [161,162]. Lysine-based dendrimer architectures were also employed against atherosclerosis, with dendritic assemblage in arterial walls resulting in the controlled release and therapeutic delivery of NO $[163,164]$. Biocompatible and functionalized dendritic structures with cyclic RGD peptide containing entrapped 76Be has been site-specifically applied for PET imaging in mice. Streptokinase-modified dendrimers synthesized with different types of polymers (PLGA or chitosan or PEG, glycol chitosan) were shown to sustain the delivery of anti-thrombotic agents in the circulation [152,163]. Figure 7 presents the general structure of dendrimers. 

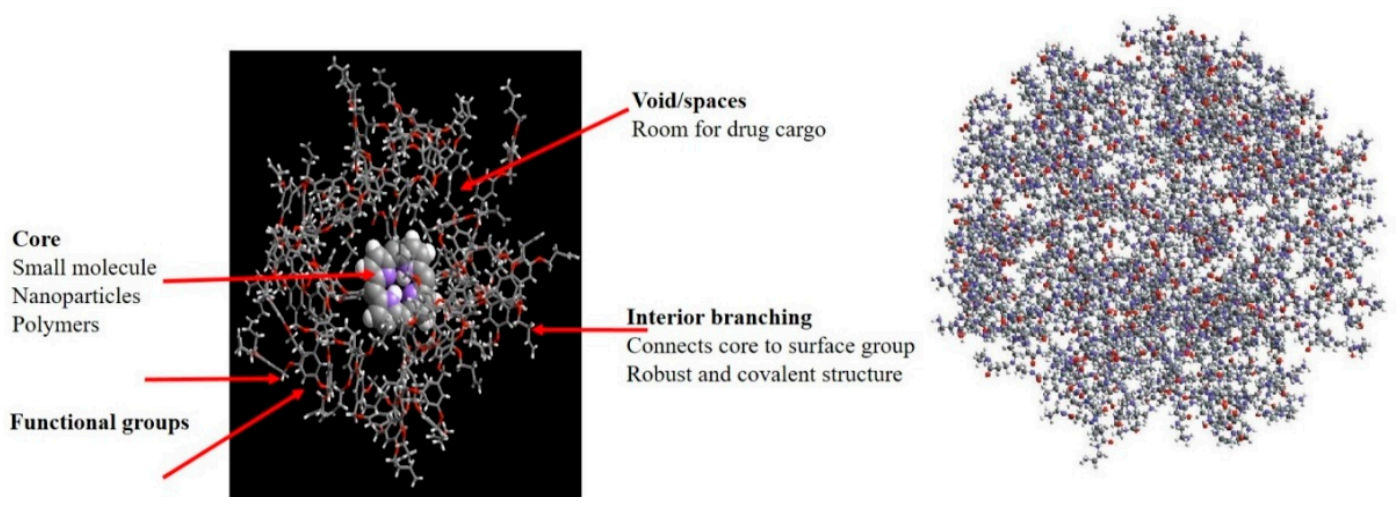

Figure 7. Schematic representation of dendrimers.

\subsection{Carbon Nanotubes}

The architectural assembly of CNTs can be described as molded or wrapped grapheme sheets. The defined structure of CNTs provides significant physiochemical properties, enhanced surface area, high optical properties, strong mechanical stability, and enhanced electrical conductivity.

Many studies reported the lack of toxicity of CNTs to deliver a variety of biological active molecules in vitro and in vivo for use in biomedical fields. For example, application of CNTs to cultured cardiomyocytes was shown to augment their viability and proliferation and to induce their maturation as reported when evaluating their electrophysiological features, while these systems can provide support to the endothelial cells in blood vessels for supplying oxygen to the heart muscle [165-167]. Garibaldi and coworkers [168] explored the potential of CNTs as biocompatible probes for applications in cardiomyocyte research. The authors reported that highly purified single walled CNTs had no toxic effects on the H9c2(2-1) rat cell line as seen by an estimation of cell proliferation and viability vs. apoptosis (tryptan blue exclusion, flow cytometry) and of morphological changes under light microscopy, supporting further work for CVD diagnosis and treatment.

\subsection{Quantum Dots}

QDs are nanocrystals semiconductor with an average diameter of $10 \mathrm{~nm}$. They possess size-dependent fluorescent properties and display different quantized energy levels. As QDs have some limitations regarding the clinical safety since they were use heavy metals that might cause toxicity or other side effects, recent work was developed to prepare heavy metal-free QDs that are less toxic [169]. QDs of cadmium selenite encapsulated with zinc sulphide were developed over which polar polymeric biomolecules can be coated for targeted delivery as shown on Figure 8.

Ferrara and coworkers [170,171] explored different possibilities of QDs for stimulation of cell adhesion molecules in targeting vascular diseases. In this purpose, QDs were functionalized with specific antibodies directed to target specific types of CVDs. Yan et al. [172] evaluated the vascular toxicity of mercapto-succinic acid-capped CdTe QDs in vitro. The authors showed that CdTe QDs dose-dependently reduced the viability of human umbilical vein endothelial cells (HUVECs), indicating CdTe QDs induced significant endothelial toxicity. The results of immunofluorescence and cytometric analyses revelaed that QDs elicited mitochondrial network fragmentation and significant oxidative stress along with a disruption of membrane potential, suggesting that exposure to QDs is of significant risk for the development of CVDs. Gilaizik et al. [173] worked on QDs and elaborated optical features with great potential as imaging tools compared with other traditional dyes, but again systemic toxicity limited their application in vivo. Vascular inflammation is one of the features that take part in CVDs such as poor prognosis and restenosis with enhanced numbers of monocyte-derived macrophages (MDMs). This study reported the structural stability, cellular uptake, physiochemical characteristics and biodistribution 
of MDM-targeted liposomal QDs (LipQDs) following local intra-luminal intervention of LipQDs in carotid injured rat relative to systemic intervention and imaging of QDs in the arterial tissues. Compared with free QDs, the LipQDs had versatile properties such as fluorescent stability, increased accumulation and retention for up to $24 \mathrm{~h}$, and targeting delivery enabling MDM imaging that may serve for screening purposes in injured arteries.

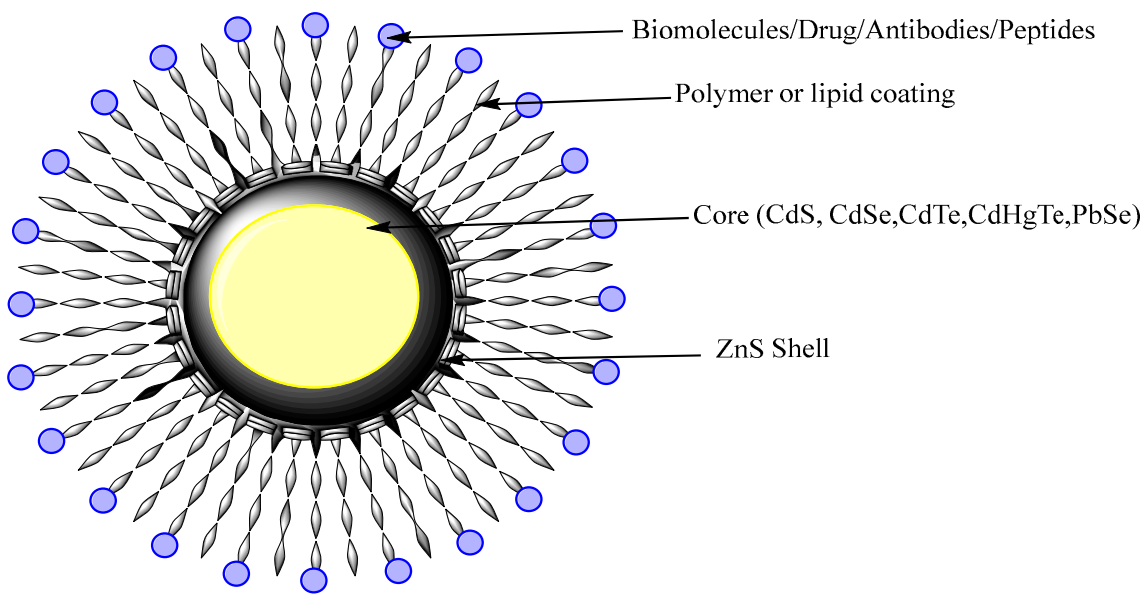

Figure 8. Schematic diagram of QDs. QDs have a core structure of heavy metal that provides fluorescence. The shell stabilizes the core and polymeric coating direct the targeted or active delivery.

\section{Mechanisms of Nanodiagnosis, Imaging, and Nanotreatment of CVDs}

The properties of nanomaterials including the multi-functionality and dual responsive modalities of inorganic (metal-based NPs), organic (polymer-based NPs), carbon-based (graphene), and lipid-based NPs make them promising tools in the field of CVD theranostics. As mentioned earlier, various biomarkers (troponin I, cTnT) have been employed in different diagnosis methods (ECL, EC, PEC, etc.) of CVDs [132,174]. Further improvements have been performed to enhance the efficiency of NPs for CVD detection using such biomarkers.

Electrochemical immunosensors composed of bioreceptor elements (antibodies, DNA, cells, enzymes, etc) have been functionalized on the surface of different NPs to improve their suitability as diagnosis tools. An amperometric sensor for the detection of cTnT using an ionic organic molecule and chitosan-coated AuNPs that analyze the changes in electrical currents caused by oxidation and reduction in biochemical reactions was created for theranostic implementation $[175,176]$. The nanomaterials used to enhance the ability of chemical biomarker for CVDs diagnosis include, among others, AuNPs, graphene oxide, $\mathrm{Co}_{3} \mathrm{O}_{4}, \mathrm{AgNPs}$, MOFs carbon dots, and $\mathrm{Fe}_{3} \mathrm{O}_{4}$ NPs. The intrinsic ability of NPs for external and internal drug transportation make them ideal carrier systems for imaging in CVDs. Gd.DTPA encapsulation in PLGA or polylactide-PEG NPs was reported to support a prolonged availability of the compound in the blood circulation for early diagnosis and imaging at the disease site [177]. SPIONs have been broadly used as contrast agents in several diagnosis, imaging, and treatment methods. Gd NPs act as T1 contrast agents while $\mathrm{Fe}_{3} \mathrm{O}_{4}$ acts as a T2 contrast agent. A combined, dual model system was developed to take advantage of both effects of $\mathrm{T} 1$ and $\mathrm{T} 2$ contrast agents. Core-shell $\mathrm{Fe}_{3} \mathrm{O}_{4} / \mathrm{Gd}_{2} \mathrm{O}_{3}$ nanocubes were fabricated to overcome the fasle imaging signals during implementation in vivo. Further functionalization of these NPs with an antibody against profilin-1 resulted in effective imaging and targeting of the atherosclerotic plaque in the carotid artery [178]. Coating of iron oxide NPs with gold can also afford protection against electrochemical reactions. Such NPs labeled with $99 \mathrm{mTc}$ and coated with annexin V enabled the targeting of apoptotic macrophages for a dual modal detection of vulnerable plaques. Treatment approaches used for clot dissolution include the use of nanovesicles directly targeting and binding to integrin GPIIb-IIIla and P-selectin on activated platelets. Fluorescent imaging was used to monitor the status of clots in the systemic circulation. Apart from thrombolytic 
agents, several techniques have been used to address thrombosis $[177,179]$. PLGA NPs encapsulated with small $\mathrm{Fe}_{3} \mathrm{O}_{4}$ NPs and perfluorohexane were modified with a CREKA peptide for imaging and thrombolysis. NPs have been also used with larger devices to recanalize the arteries and achieve required features. Stent-coated polymeric NPs loaded with sirolimus were used as very efficient systems for optimal outcomes. A multi-functional bioresorable electronic stent was successfully generated to promote flow sensing, wireless power data transmission, inflammation suppression, and localized drug delivery [177]. Mesoporous silica AuNPs were also integrated for their enhanced efficacy in CVDs in several in vitro, ex vivo, and in vivo settings [180].

The mechanisms of action of these multiple responsive NPs are depicted on Figure 9 showing how their functionalization supports nanotreatment and nanodiagnosis applications at the disease site and how they act as biosensors. Specifically, Figure 9A shows an USPION system functionalized with 99Tc label and annexin V and displaying a phosphotidylserine on their surface for dual modality imaging and to target apoptotic cells at the disease site. The method of implementation serves as a basis for the nanodiagnosis and nanotreatment of CVDs and functionalization/coating further amplifies the theranostic benefits for the diseases.

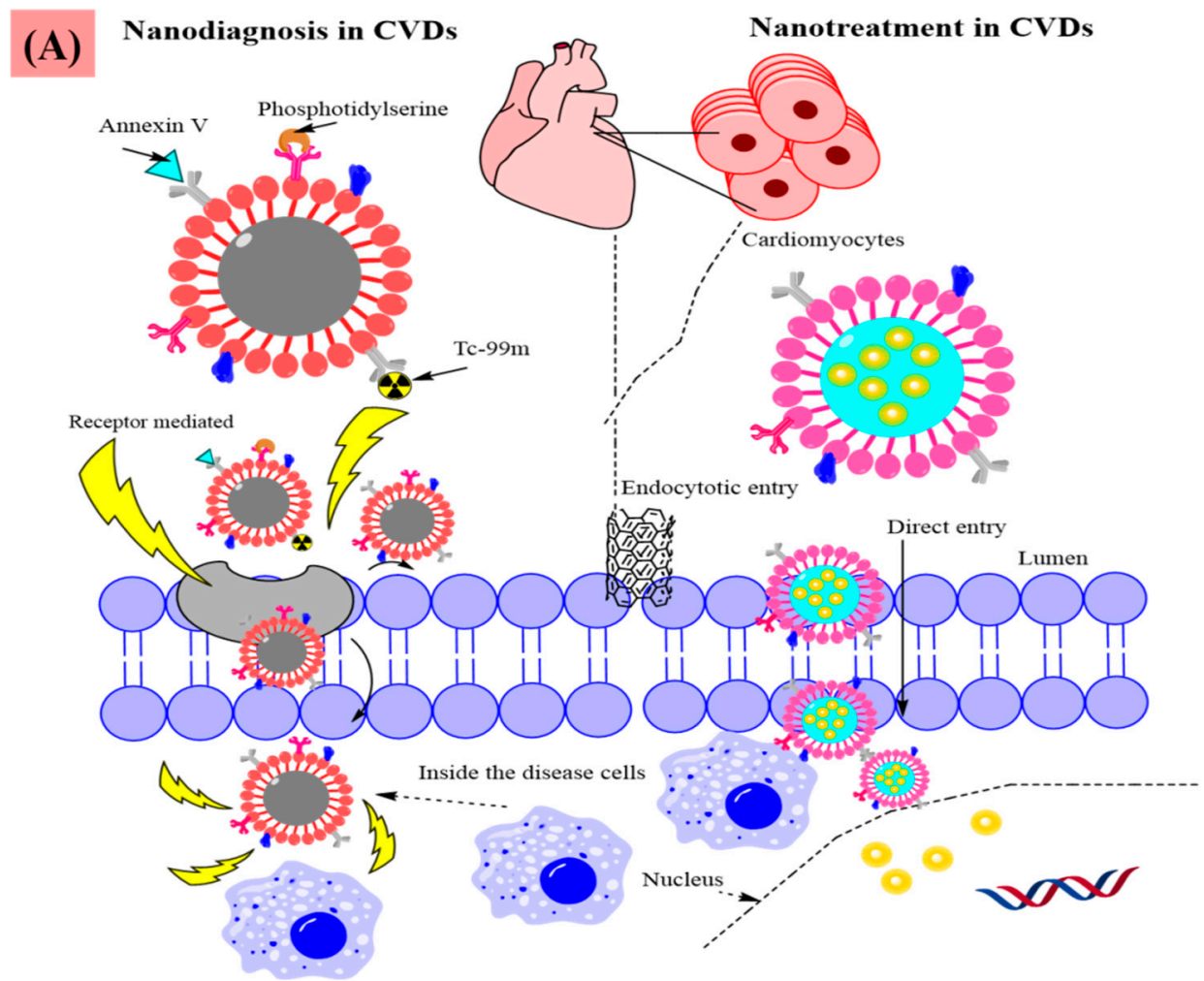

Figure 9. Cont. 




Figure 9. Mechanisms of nanodiagnosis, imaging, and nanotreatment of CVDs. (A) Mechanistic nanocarrier-based approach for the diagnosis and treatment of cardiomyocytes in CVDs with enhanced sensitivity against the cardiobiomarker. (B) Application of the biosensor approach to detect cardiac markers in CVD patients' blood where the sensor uses biocatalysts such as DNA, enzymes, cell, antibody to detect specific cardiobiomarkers.

\section{Conclusions, Challenges, and Perspectives}

Nanomaterial applications may significantly enhance the number of tools available to clinicians against several life threating diseases such as CVDs. The potential use and efficacy of different nanomaterials including liposomes, CNTs, and polymeric NPs are considered as breakthroughs in a world of conventional materials. New strategies and techniques will emerge with advancements in nanoscience. The predictability of the treatments of CVDs can be further improved and transformed as more promises in nanomaterials are becoming a reality.

Existing medical problems for CVDs include the generation of simple, detailed clinical diagnostic decisions and the regular monitoring of drug responses. Various platforms have been proposed to address such challenges. The specificity and sensitivity of diagnostic devices could be improved by nanosensors. In the diagnostic development of CVDs, biosensor engineering using biomarkers plays a critical role. For multiple disease marker detection and accurate diagnosis of heart disease, the creation of highly specific and responsive biosensor platforms using well-established surface chemistry and nanomaterials is critical. Simultaneous detection of several biomarkers with a single experiment using limited blood sample volumes significantly increases the validity of the system with reduced diagnostic costs in disease stage measurement. Combining existing methods such as microfluidics, proteomics, and polymer science with the discovery of biomarkers and the development of biosensors can also provide miniaturized, easy-to-use, accurate, and cost-effective instruments for biosensing.

While significant advances have been made in nanotechnology for the diagnosis of CVDs, early-stage diagnosis is still difficult because symptoms are unclear and as the level of expression of early-stage cardiac biomarkers is relatively low for detection, making nanotechnological testing still challenging. The sensitivity and specificity of the biomarker is an important concern. Previous research showed that there may be inadequate single markers, leading to a lack of sensitivity and specificity for correct CVD diagnosis. Due to the uncertainty, heterogeneity, and variability of pathogenesis in various populations, 
it is impractical to have clear diagnosis results using one single biomarker. Additionally, during the development of pathologies, biomarkers may be differently controlled.

The expanded use of nanomaterials in a wide variety of biomedical applications, on the other hand, also raises concerns regarding their toxicity. It is stated that the morphological and physicochemical properties of nanomaterials useful for their biomedical applications play an important role in determining their toxicity in various organs including the liver, kidney, skin, brain, heart, etc. While nanomaterials have significant undesirable side effects in various experimental models, their toxicity may be minimized or eliminated by engineering their surfaces with various types of natural or synthetic polymers or other compounds. While many studies are available focusing on biomedical applications of nanomaterials and on their toxicity, there is still no in-depth information available covering all these aspects.

Finally, more research is needed to highlight the combination of advanced computational methods (e.g., machine learning) capable of developing objective and automated algorithms for large-scale and high-dimensional-multiplexed data analysis, which are intended to greatly enhance the efficiency and accuracy of diagnosis of CVDs in the future.

Author Contributions: All authors contributed equally to this paper. Conceptualization, F.S., M.B., M.M., A.R., and M.N.Z.; Investigation, F.S., M.B., M.M., A.R., T.B., and S.B.; Writing-original draft preparation, F.S., M.B., M.M., A.R., and M.N.Z.; Writing—review and editing, M.C., M.N.Z., and S.B.; supervision, A.R. All authors have read and agreed to the published version of the manuscript.

Funding: This work was supported by the Saarland University within the funding programme Open Access Publishing.

Institutional Review Board Statement: Not applicable.

Informed Consent Statement: Not applicable.

Data Availability Statement: Not applicable.

Conflicts of Interest: The authors declare no conflict of interest.

\section{References}

1. WHO. Cardiovascular Diseases (CVDs). 2017. Available online: http://www.who.int/news-room/fact-sheets/detail/ cardiovascular-diseases-(cvds) (accessed on 4 July 2018).

2. Flora, G.D.; Nayak, M.K. A brief review of cardiovascular diseases, associated risk factors and current treatment regimes. Curr. Pharm. Des. 2019, 25, 4063-4084. [CrossRef]

3. Zamani, P.; Fereydouni, N.; Butler, A.E.; Navashenaq, J.G.; Sahebkar, A. The therapeutic and diagnostic role of exosomes in cardiovascular diseases. Trends Cardiovasc. Med. 2019, 29, 313-323. [CrossRef]

4. Braunwald, E. Cardiomyopathies: An overview. Circ. Res. 2017, 121, 711-721. [CrossRef]

5. Yusuf, S.; Joseph, P.; Rangarajan, S.; Islam, S.; Mente, A.; Hystad, P.; Brauer, M.; Kutty, V.R.; Gupta, R.; Wielgosz, A. Modifiable risk factors, cardiovascular disease, and mortality in 155722 individuals from 21 high-income, middle-income, and low-income countries (PURE): A prospective cohort study. Lancet 2020, 395, 795-808. [CrossRef]

6. Chiba, A.; Watanabe-Takano, H.; Miyazaki, T.; Mochizuki, N. Cardiomyokines from the heart. Cell. Mol. Life Sci. 2018, 75, 1349-1362. [CrossRef]

7. Putzu, A.; de Carvalho, C.M.P.D.; de Almeida, J.P.; Belletti, A.; Cassina, T.; Landoni, G.; Hajjar, L.A. Perioperative statin therapy in cardiac and non-cardiac surgery: A systematic review and meta-analysis of randomized controlled trials. Ann. Intensive Care 2018, 8, 95. [CrossRef]

8. Diaconu, C.C.; Marcu, D.R.; Bratu, O.G.; Stanescu, A.M.A.; Gheorghe, G.; Hlescu, A.A.; Mischianu, D.L.; Manea, M. Beta-blockers in cardiovascular therapy: A review. J. Mind Med. Sci. 2019, 6, 216-223. [CrossRef]

9. Zhang, P.; Zhu, L.; Cai, J.; Lei, F.; Qin, J.-J.; Xie, J.; Liu, Y.-M.; Zhao, Y.-C.; Huang, X.; Lin, L. Association of inpatient use of angiotensin converting enzyme inhibitors and angiotensin II receptor blockers with mortality among patients with hypertension hospitalized with COVID-19. Circ. Res. 2020, 126, 1671-1681. [CrossRef] [PubMed]

10. Ambrosy, A.P.; Mentz, R.J.; Fiuzat, M.; Cleland, J.G.; Greene, S.J.; O'Connor, C.M.; Teerlink, J.R.; Zannad, F.; Solomon, S.D. The role of angiotensin receptor-neprilysin inhibitors in cardiovascular disease-existing evidence, knowledge gaps, and future directions. Eur. J. Heart Fail. 2018, 20, 963-972. [CrossRef] [PubMed]

11. Rodriguez-Araujo, G.; Krentz, A.J. Utility of invasive and non-invasive cardiovascular research. In Translational Research Methods in Diabetes, Obesity, and Nonalcoholic Fatty Liver Disease: A Focus on Early Phase Clinical Drug Development; Springer: Cham, Switzerland, 2019; pp. 275-308. 
12. Shi, C.; Xie, H.; Ma, Y.; Yang, Z.; Zhang, J. Nanoscale technologies in highly sensitive diagnosis of cardiovascular diseases. Front. Bioeng. Biotechnol. 2020, 8, 531. [CrossRef]

13. Morris, S.A.; Slesnick, T.C. Magnetic resonance imaging. In Visual Guide to Neonatal Cardiology; John Wiley \& Sons Ltd.: Hoboken, NJ, USA, 2018; pp. 104-108.

14. Alsharqi, M.; Woodward, W.; Mumith, J.; Markham, D.; Upton, R.; Leeson, P. Artificial intelligence and echocardiography. Echo Res. Pract. 2018, 5, R115-R125. [CrossRef]

15. Picard, F.; Sayah, N.; Spagnoli, V.; Adjedj, J.; Varenne, O. Vasospastic angina: A literature review of current evidence. Arch. Cardiovasc. Dis. 2019, 112, 44-55. [CrossRef] [PubMed]

16. Schoepf, U.J. CT of the Heart; Humana Press: Totowa, NJ, USA, 2019.

17. Oikonomou, E.K. Molecular Imaging to Guide Precision Diagnosis and Prevention of Cancer Therapeutics-Related Cardiac Dysfunction; Taylor \& Francis: Abingdon, UK, 2020.

18. Clerico, A.; Lippi, G. The state-of-the-art of "high-sensitivity" immunoassay for measuring cardiac troponin I and T. J. Lab. Precis. Med. 2018, 3, 53. [CrossRef]

19. Chandarana, M.; Curtis, A.; Hoskins, C. The use of nanotechnology in cardiovascular disease. Appl. Nanosci. 2018, 8, 1607-1619. [CrossRef]

20. Raber, I.; McCarthy, C.P.; Vaduganathan, M.; Bhatt, D.L.; Wood, D.A.; Cleland, J.G.; Blumenthal, R.S.; McEvoy, J.W. The rise and fall of aspirin in the primary prevention of cardiovascular disease. Lancet 2019, 393, 2155-2167. [CrossRef]

21. Univers, J.; Long, C.; Tonks, S.A.; Freeman, M.B. Systemic hypersensitivity reaction to endovascular stainless steel stent. J. Vasc. Surg. 2018, 67, 615-617. [CrossRef] [PubMed]

22. Bejarano, J.; Navarro-Marquez, M.; Morales-Zavala, F.; Morales, J.O.; Garcia-Carvajal, I.; Araya-Fuentes, E.; Flores, Y.; Verdejo, H.E.; Castro, P.F.; Lavandero, S. Nanoparticles for diagnosis and therapy of atherosclerosis and myocardial infarction: Evolution toward prospective theranostic approaches. Theranostics 2018, 8, 4710. [CrossRef]

23. Tian, L.; Lu, L.; Feng, J.; Melancon, M.P. Radiopaque nano and polymeric materials for atherosclerosis imaging, embolization and other catheterization procedures. Acta Pharm. Sin. B 2018, 8, 360-370. [CrossRef]

24. Richardson, J.J.; Caruso, F. Nanomedicine toward 2040. Nano Lett. 2020, 20, 1481-1482. [CrossRef]

25. Barani, M.; Torkzadeh-Mahani, M.; Mirzaei, M.; Nematollahi, M.H. Comprehensive evaluation of gene expression in negative and positive trigger-based targeting niosomes in HEK-293 cell line. Iran. J. Pharm. Res. IJPR 2020, $19,166$.

26. Bilal, M.; Barani, M.; Sabir, F.; Rahdar, A.; Kyzas, G.Z. Nanomaterials for the treatment and diagnosis of Alzheimer's disease: An overview. NanoImpact 2020, 20, 100251. [CrossRef]

27. Mombini, S.; Mohammadnejad, J.; Bakhshandeh, B.; Narmani, A.; Nourmohammadi, J.; Vahdat, S.; Zirak, S. Chitosan-PVA-CNT nanofibers as electrically conductive scaffolds for cardiovascular tissue engineering. Int. J. Biol. Macromol. 2019, 140, $278-287$. [CrossRef]

28. Mukhtar, M.; Ali, H.; Ahmed, N.; Munir, R.; Talib, S.; Khan, A.S.; Ambrus, R. Drug delivery to macrophages: A review of nano-therapeutics targeted approach for inflammatory disorders and cancer. Expert Opin. Drug Deliv. 2020, 17, 1239-1257. [CrossRef] [PubMed]

29. Sevostyanov, M.; Baikin, A.; Sergienko, K.; Shatova, L.; Kirsankin, A.; Baymler, I.; Shkirin, A.; Gudkov, S. Biodegradable stent coatings on the basis of PLGA polymers of different molecular mass, sustaining a steady release of the thrombolityc enzyme streptokinase. React. Funct. Polym. 2020, 150, 104550. [CrossRef]

30. Sun, J.; Sun, K.; Bai, K.; Chen, S.; Wang, F.; Zhao, F.; Hong, N.; Hu, H. A novel braided biodegradable stent for use in congenital heart disease: Short-term results in porcine iliac artery. J. Biomed. Mater. Res. Part A 2019, 107, 1667-1677. [CrossRef]

31. Omid, S.O.; Goudarzi, Z.; Kangarshahi, L.M.; Mokhtarzade, A.; Bahrami, F. Self-expanding stents based on shape memory alloys and shape memory polymers. J. Compos. Compd. 2020, 2, 92-98.

32. Maleki, B.; Alinezhad, H.; Atharifar, H.; Tayebee, R.; Mofrad, A.V. One-pot synthesis of polyhydroquinolines catalyzed by $\mathrm{ZnCl}_{2}$ supported on nano $\mathrm{Fe}_{3} \mathrm{O}_{4} @ \mathrm{SiO}_{2}$. Org. Prep. Proced. Int. 2019, 51, 301-309. [CrossRef]

33. Cervadoro, A.; Palomba, R.; Vergaro, G.; Cecchi, R.; Menichetti, L.; Decuzzi, P.; Emdin, M.; Luin, S. Targeting inflammation with nanosized drug delivery platforms in cardiovascular diseases: Immune cell modulation in atherosclerosis. Front. Bioeng. Biotechnol. 2018, 6, 177. [CrossRef]

34. Sandoval-Yañez, C.; Castro Rodriguez, C. Dendrimers: Amazing platforms for bioactive molecule delivery systems. Materials 2020, 13, 570. [CrossRef]

35. Dizaj, S.M.; Rad, A.A.; Safaei, N.; Salatin, S.; Ahmadian, E.; Sharifi, S.; Vahed, S.Z.; Lotfipour, F.; Shahi, S. The application of nanomaterials in cardiovascular diseases: A review on drugs and devices. J. Pharm. Pharm. Sci. 2019, 22, 501-515. [CrossRef]

36. Thompson, L.C.; Sheehan, N.L.; Walters, D.M.; Lust, R.M.; Brown, J.M.; Wingard, C.J. Airway exposure to modified multi-walled carbon nanotubes perturbs cardiovascular adenosinergic signaling in mice. Cardiovasc. Toxicol. 2019, 19, 168-177. [CrossRef]

37. Giménez, V.M.M.; Fuentes, L.B.; Kassuha, D.E.; Manucha, W. Current Drug Nano-targeting Strategies for Improvement in the diagnosis and treatment of prevalent pathologies such as cardiovascular and renal diseases. Curr. Drug Targets 2019, 20, 1496-1504. [CrossRef]

38. Tu, Y.; Sun, Y.; Fan, Y.; Cheng, Z.; Yu, B. Multimodality molecular imaging of cardiovascular disease based on nanoprobes. Cell. Physiol. Biochem. 2018, 48, 1401-1415. [CrossRef] 
39. Li, T.; Liang, W.; Xiao, X.; Qian, Y. Nanotechnology, an alternative with promising prospects and advantages for the treatment of cardiovascular diseases. Int. J. Nanomed. 2018, 13, 7349. [CrossRef]

40. Deng, Y.; Zhang, X.; Shen, H.; He, Q.; Wu, Z.; Liao, W.; Yuan, M. Application of the nano-drug delivery system in treatment of cardiovascular diseases. Front. Bioeng. Biotechnol. 2020, 7, 489. [CrossRef] [PubMed]

41. Su, M.; Dai, Q.; Chen, C.; Zeng, Y.; Chu, C.; Liu, G. Nano-medicine for thrombosis: A precise diagnosis and treatment strategy. Nano-Micro Lett. 2020, 12, 96. [CrossRef]

42. Solaimuthu, A.; Vijayan, A.N.; Murali, P.; Korrapati, P.S. Nano-biosensors and their relevance in tissue engineering. Curr. Opin. Biomed. Eng. 2020, 13, 84-93. [CrossRef]

43. Lenz, T.; Nicol, P.; Castellanos, M.I.; Engel, L.-C.; Lahmann, A.L.; Alexiou, C.; Joner, M. Small dimension-big impact! Nanoparticle-enhanced non-invasive and intravascular molecular imaging of atherosclerosis in vivo. Molecules 2020, 25, 1029. [CrossRef] [PubMed]

44. Christodoulides, N.; McRae, M.P.; Simmons, G.W.; Modak, S.S.; McDevitt, J.T. Sensors that learn: The evolution from taste fingerprints to patterns of early disease detection. Micromachines 2019, 10, 251. [CrossRef]

45. Li, T.; Feng, Z.-Q.; Qu, M.; Yan, K.; Yuan, T.; Gao, B.; Wang, T.; Dong, W.; Zheng, J. Core/shell piezoelectric nanofibers with spatial self-orientated $\beta$-phase nanocrystals for real-time micropressure monitoring of cardiovascular walls. ACS Nano 2019, 13, 10062-10073. [CrossRef] [PubMed]

46. Barani, M.; Mirzaei, M.; Torkzadeh-Mahani, M.; Adeli-sardou, M. Evaluation of carum-loaded niosomes on breast cancer cells: Physicochemical properties, in vitro cytotoxicity, flow cytometric, DNA fragmentation and cell migration assay. Sci. Rep. 2019, 9, 7139. [CrossRef]

47. Barani, M.; Mirzaei, M.; Torkzadeh-Mahani, M.; Lohrasbi-Nejad, A.; Nematollahi, M.H. A new formulation of hydrophobin-coated niosome as a drug carrier to cancer cells. Mater. Sci. Eng. C 2020, 113, 110975. [CrossRef] [PubMed]

48. Barani, M.; Mirzaei, M.; Torkzadeh-Mahani, M.; Nematollahi, M.H. Lawsone-loaded Niosome and its antitumor activity in MCF-7 breast Cancer cell line: A Nano-herbal treatment for Cancer. DARU J. Pharm. Sci. 2018, 26, 11-17. [CrossRef]

49. Barani, M.; Nematollahi, M.H.; Zaboli, M.; Mirzaei, M.; Torkzadeh-Mahani, M.; Pardakhty, A.; Karam, G.A. In silico and in vitro study of magnetic niosomes for gene delivery: The effect of ergosterol and cholesterol. Mater. Sci. Eng. C 2019, 94, 234-246. [CrossRef]

50. Barani, M.; Sabir, F.; Rahdar, A.; Arshad, R.; Z Kyzas, G. Nanotreatment and nanodiagnosis of prostate cancer: Recent updates. Nanomaterials 2020, 10, 1696. [CrossRef] [PubMed]

51. Saravani, R.; Sargazi, S.; Saravani, R.; Rabbani, M.; Rahdar, A.; Taboada, P. Newly crocin-coated magnetite nanoparticles induce apoptosis and decrease VEGF expression in breast carcinoma cells. J. Drug Deliv. Sci. Technol. 2020, 60, 101987. [CrossRef]

52. Das, S.S.; Bharadwaj, P.; Bilal, M.; Barani, M.; Rahdar, A.; Taboada, P.; Bungau, S.; Kyzas, G.Z. Stimuli-responsive polymeric nanocarriers for drug delivery, imaging, and theragnosis. Polymers 2020, 12, 1397. [CrossRef] [PubMed]

53. Davarpanah, F.; Yazdi, A.K.; Barani, M.; Mirzaei, M.; Torkzadeh-Mahani, M. Magnetic delivery of antitumor carboplatin by using PEGylated-Niosomes. DARU J. Pharm. Sci. 2018, 26, 57-64. [CrossRef]

54. Ebrahimi, A.K.; Barani, M.; Sheikhshoaie, I. Fabrication of a new superparamagnetic metal-organic framework with core-shell nanocomposite structures: Characterization, biocompatibility, and drug release study. Mater. Sci. Eng. C 2018, 92, 349-355. [CrossRef] [PubMed]

55. Hajizadeh, M.R.; Maleki, H.; Barani, M.; Fahmidehkar, M.A.; Mahmoodi, M.; Torkzadeh-Mahani, M. In vitro cytotoxicity assay of D-limonene niosomes: An efficient nano-carrier for enhancing solubility of plant-extracted agents. Res. Pharm. Sci. 2019, 14, 448.

56. Hajizadeh, M.R.; Parvaz, N.; Barani, M.; Khoshdel, A.; Fahmidehkar, M.A.; Mahmoodi, M.; Torkzadeh-Mahani, M. Diosgeninloaded niosome as an effective phytochemical nanocarrier: Physicochemical characterization, loading efficiency, and cytotoxicity assay. DARU J. Pharm. Sci. 2019, 27, 329-339. [CrossRef] [PubMed]

57. Rahdar, A.; Hajinezhad, M.R.; Nasri, S.; Beyzaei, H.; Barani, M.; Trant, J.F. The synthesis of methotrexate-loaded F127 microemulsions and their in vivo toxicity in a rat model. J. Mol. Liq. 2020, 313, 113449. [CrossRef]

58. Rahdar, A.; Taboada, P.; Hajinezhad, M.R.; Barani, M.; Beyzaei, H. Effect of tocopherol on the properties of Pluronic F127 microemulsions: Physico-chemical characterization and in vivo toxicity. J. Mol. Liq. 2019, 277, 624-630. [CrossRef]

59. Torkzadeh-Mahani, M.; Zaboli, M.; Barani, M.; Torkzadeh-Mahani, M. A combined theoretical and experimental study to

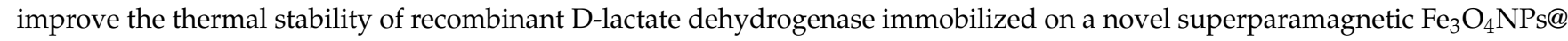
metal-organic framework. Appl. Organomet. Chem. 2020, 34, e5581. [CrossRef]

60. Rahdar, A.; Aliahmad, M.; Samani, M.; HeidariMajd, M.; Susan, M.A.B.H. Synthesis and characterization of highly efficacious Fe-doped ceria nanoparticles for cytotoxic and antifungal activity. Ceram. Int. 2019, 45, 7950-7955. [CrossRef]

61. Rahdar, A.; Hajinezhad, M.R.; Sankar, V.S.; Askari, F.; Noura, M.; Kyzas, G.Z. Synthesis, characterization, and intraperitoneal biochemical studies of zinc oxide nanoparticles in Rattus norvegicus. Appl. Phys. A 2020, 126, 347. [CrossRef]

62. Taimoory, S.M.; Rahdar, A.; Aliahmad, M.; Sadeghfar, F.; Hajinezhad, M.R.; Jahantigh, M.; Shahbazi, P.; Trant, J.F. The synthesis and characterization of a magnetite nanoparticle with potent antibacterial activity and low mammalian toxicity. J. Mol. Liq. 2018, 265, 96-104. [CrossRef]

63. Gofman, J.W.; Lindgren, F.; Elliott, H.; Mantz, W.; Hewitt, J.; Strisower, B.; Herring, V.; Lyon, T.P. The role of lipids and lipoproteins in atherosclerosis. Science 1950, 111, 166-186. [CrossRef] 
64. Bayoumi, A.S.; Aonuma, T.; Teoh, J.-p.; Tang, Y.-l.; Kim, I.-m. Circular noncoding RNAs as potential therapies and circulating biomarkers for cardiovascular diseases. Acta Pharmacol. Sin. 2018, 39, 1100-1109. [CrossRef]

65. Soler-Botija, C.; Gálvez-Montón, C.; Bayes Genis, A. Epigenetic biomarkers in cardiovascular diseases. Front. Genet. 2019, 10, 950. [CrossRef]

66. Ghantous, C.M.; Kamareddine, L.; Farhat, R.; Zouein, F.A.; Mondello, S.; Kobeissy, F.; Zeidan, A. Advances in cardiovascular biomarker discovery. Biomedicines 2020, 8, 552. [CrossRef] [PubMed]

67. El-Lebedy, D.; Rasheed, E.; Kafoury, M.; Abd-El Haleem, D.; Awadallah, E.; Ashmawy, I. Anti-apolipoprotein A-1 autoantibodies as risk biomarker for cardiovascular diseases in type 2 diabetes mellitus. J. Diabetes Its Complicat. 2016, 30, 580-585. [CrossRef] [PubMed]

68. Ghodake, S.; Ghumbre, S.; Deshmukh, S. Electrocardiogram signal denoising using hybrid filtering for cardiovascular diseases prediction. In Techno-Societal 2018; Springer: Berlin/Heidelberg, Germany, 2020; pp. 271-278.

69. Wang, Y.; Osborne, M.T.; Tung, B.; Li, M.; Li, Y. Imaging cardiovascular calcification. J. Am. Heart Assoc. 2018, 7, e008564. [CrossRef] [PubMed]

70. Scali, M.C.; Zagatina, A.; Ciampi, Q.; Cortigiani, L.; D’Andrea, A.; Daros, C.B.; Zhuravskaya, N.; Kasprzak, J.D.; WierzbowskaDrabik, K.; e Silva, J.L.d.C. Lung ultrasound and pulmonary congestion during stress echocardiography. JACC Cardiovasc. Imaging 2020, 13, 2085-2095. [CrossRef]

71. Chou, T.-H.; Janse, S.; Sinusas, A.J.; Stacy, M.R. SPECT/CT imaging of lower extremity perfusion reserve: A non-invasive correlate to exercise tolerance and cardiovascular fitness in patients undergoing clinically indicated myocardial perfusion imaging. J. Nucl. Cardiol. 2020, 27, 1923-1933. [CrossRef] [PubMed]

72. Lindner, J.R. Molecular imaging of cardiovascular disease with contrast-enhanced ultrasonography. Nat. Rev. Cardiol. 2009, 6, 475. [CrossRef]

73. Osborn, E.A.; Jaffer, F.A. The advancing clinical impact of molecular imaging in CVD. JACC Cardiovasc. Imaging 2013, 6, 1327-1341. [CrossRef] [PubMed]

74. Şahin, B.; İlgün, G. Risk factors of deaths related to cardiovascular diseases in World Health Organization (WHO) member countries. Health Soc. Care Community 2020. [CrossRef]

75. Zhu, C.; Yang, G.; Li, H.; Du, D.; Lin, Y. Electrochemical sensors and biosensors based on nanomaterials and nanostructures. Anal. Chem. 2015, 87, 230-249. [CrossRef]

76. Chen, K.-I.; Li, B.-R.; Chen, Y.-T. Silicon nanowire field-effect transistor-based biosensors for biomedical diagnosis and cellular recording investigation. Nano Today 2011, 6, 131-154. [CrossRef]

77. Surya, S.G.; Majhi, S.M.; Agarwal, D.K.; Lahcen, A.A.; Yuvaraja, S.; Chappanda, K.N.; Salama, K.N. A label-free aptasensor FET based on Au nanoparticle decorated $\mathrm{Co}_{3} \mathrm{O}_{4}$ nanorods and a SWCNT layer for detection of cardiac troponin T protein. J. Mater. Chem. B 2020, 8, 18-26. [CrossRef] [PubMed]

78. Chen, A.; Chatterjee, S. Nanomaterials based electrochemical sensors for biomedical applications. Chem. Soc. Rev. 2013, 42, 5425-5438. [CrossRef] [PubMed]

79. Song, Y.; Shen, Y.; Chen, J.; Song, Y.; Gong, C.; Wang, L. A pH-dependent electrochemical immunosensor based on integrated macroporous carbon electrode for assay of carcinoembryonic antigen. Electrochim. Acta 2016, 211, 297-304. [CrossRef]

80. Wang, B.; Jing, R.; Qi, H.; Gao, Q.; Zhang, C. Label-free electrochemical impedance peptide-based biosensor for the detection of cardiac troponin I incorporating gold nanoparticles modified carbon electrode. J. Electroanal. Chem. 2016, 781, 212-217. [CrossRef]

81. Sharma, A.; Bhardwaj, J.; Jang, J. Label-free, highly sensitive electrochemical aptasensors using polymer-modified reduced graphene oxide for cardiac biomarker detection. ACS Omega 2020, 5, 3924-3931. [CrossRef]

82. Olubamwo, O.O.; Virtanen, J.K.; Voutilainen, A.; Kauhanen, J.; Pihlajamäki, J.; Tuomainen, T.-P. Association of fatty liver index with the risk of incident cardiovascular disease and acute myocardial infarction. Eur. J. Gastroenterol. Hepatol. 2018, 30, 1047-1054. [CrossRef]

83. Grabowska, I.; Sharma, N.; Vasilescu, A.; Iancu, M.; Badea, G.; Boukherroub, R.; Ogale, S.; Szunerits, S. Electrochemical aptamer-based biosensors for the detection of cardiac biomarkers. ACS Omega 2018, 3, 12010-12018. [CrossRef]

84. Cao, Z.; Jia, Y.; Zhu, B. Bnp and nt-probnp as diagnostic biomarkers for cardiac dysfunction in both clinical and forensic medicine. Int. J. Mol. Sci. 2019, 20, 1820. [CrossRef] [PubMed]

85. Hicks, J.M. Fluorescence immunoassay. Hum. Pathol. 1984, 15, 112-116. [CrossRef]

86. Miao, L.; Jiao, L.; Tang, Q.; Li, H.; Zhang, L.; Wei, Q. A nanozyme-linked immunosorbent assay for dual-modal colorimetric and ratiometric fluorescent detection of cardiac troponin I. Sens. Actuators B Chem. 2019, 288, 60-64. [CrossRef]

87. Gogoi, S.; Khan, R. Fluorescence immunosensor for cardiac troponin T based on Förster resonance energy transfer (FRET) between carbon dot and MoS 2 nano-couple. Phys. Chem. Chem. Phys. 2018, 20, 16501-16509. [CrossRef]

88. Guo, Z.; Hao, T.; Du, S.; Chen, B.; Wang, Z.; Li, X.; Wang, S. Multiplex electrochemiluminescence immunoassay of two tumor markers using multicolor quantum dots as labels and graphene asconductingbridge. Biosens. Bioelectron. 2013, 44, 101-107. [CrossRef]

89. Dong, X.; Zhao, G.; Li, X.; Miao, J.; Fang, J.; Wei, Q.; Cao, W. Electrochemiluminescence immunoassay for the N-terminal pro-B-type natriuretic peptide based on resonance energy transfer between a self-enhanced luminophore composed of silver nanocubes on gold nanoparticles and a metal-organic framework of type MIL-125. Microchim. Acta 2019, 186, 811. [CrossRef] [PubMed] 
90. Wu, L.; Chu, H.; Koh, W.; Li, E. Highly sensitive graphene biosensors based on surface plasmon resonance. Opt. Express 2010, 18, 14395-14400. [CrossRef] [PubMed]

91. Chen, F.; Wu, Q.; Song, D.; Wang, X.; Ma, P.; Sun, Y. $\mathrm{Fe}_{3} \mathrm{O}_{4} @$ PDA immune probe-based signal amplification in surface plasmon resonance (SPR) biosensing of human cardiac troponin I. Colloids Surf. B Biointerfaces 2019, 177, 105-111. [CrossRef] [PubMed]

92. $\mathrm{Wu}, \mathrm{L} . ; \mathrm{Li}, \mathrm{G} . ; \mathrm{Xu}, \mathrm{X}$.; Zhu, L.; Huang, R.; Chen, X. Application of nano-ELISA in food analysis: Recent advances and challenges. TrAC Trends Anal. Chem. 2019, 113, 140-156. [CrossRef]

93. Jiao, L.; Zhang, L.; Du, W.; Li, H.; Yang, D.; Zhu, C. Au@ Pt nanodendrites enhanced multimodal enzyme-linked immunosorbent assay. Nanoscale 2019, 11, 8798-8802. [CrossRef] [PubMed]

94. Zheng, Y.; Liang, W.; Yuan, Y.; Xiong, C.; Xie, S.; Wang, H.; Chai, Y.; Yuan, R. Wavelength-resolved simultaneous photoelectrochemical bifunctional sensor on single interface: A newly in vitro approach for multiplexed DNA monitoring in cancer cells. Biosens. Bioelectron. 2016, 81, 423-430. [CrossRef] [PubMed]

95. Xue, T.-Y.; Mei, L.-P.; Xu, Y.-T.; Liu, Y.-L.; Fan, G.-C.; Li, H.-Y.; Ye, D.; Zhao, W.-W. Nanoporous semiconductor electrode captures the quantum dots: Toward ultrasensitive signal-on liposomal photoelectrochemical immunoassay. Anal. Chem. 2019, 91, 3795-3799. [CrossRef]

96. Granger, J.H.; Granger, M.C.; Firpo, M.A.; Mulvihill, S.J.; Porter, M.D. Toward development of a surface-enhanced Raman scattering (SERS)-based cancer diagnostic immunoassay panel. Analyst 2013, 138, 410-416. [CrossRef] [PubMed]

97. Fu, X.; Wang, Y.; Liu, Y.; Liu, H.; Fu, L.; Wen, J.; Li, J.; Wei, P.; Chen, L. A graphene oxide/gold nanoparticle-based amplification method for SERS immunoassay of cardiac troponin I. Analyst 2019, 144, 1582-1589. [CrossRef]

98. Shim, M.S.; Kwon, Y.J. Stimuli-responsive polymers and nanomaterials for gene delivery and imaging applications. Adv. Drug Deliv. Rev. 2012, 64, 1046-1059. [CrossRef]

99. Liu, J.; Lécuyer, T.; Seguin, J.; Mignet, N.; Scherman, D.; Viana, B.; Richard, C. Imaging and therapeutic applications of persistent luminescence nanomaterials. Adv. Drug Deliv. Rev. 2019, 138, 193-210. [CrossRef] [PubMed]

100. Zhang, C.; Wu, W.; Li, R.Q.; Qiu, W.X.; Zhuang, Z.N.; Cheng, S.X.; Zhang, X.Z. Peptide-based multifunctional nanomaterials for tumor imaging and therapy. Adv. Funct. Mater. 2018, 28, 1804492. [CrossRef]

101. Rosenkrans, Z.T.; Ferreira, C.A.; Ni, D.; Cai, W. Internally responsive nanomaterials for activatable multimodal imaging of cancer. Adv. Healthc. Mater. 2020, 2000690. [CrossRef] [PubMed]

102. Zhang, Q.; Iwakuma, N.; Sharma, P.; Moudgil, B.; Wu, C.; McNeill, J.; Jiang, H.; Grobmyer, S. Gold nanoparticles as a contrast agent for in vivo tumor imaging with photoacoustic tomography. Nanotechnology 2009, 20, 395102. [CrossRef]

103. Li, W.; Chen, X. Gold nanoparticles for photoacoustic imaging. Nanomedicine 2015, 10, 299-320. [CrossRef]

104. Rouleau, L.; Berti, R.; Ng, V.W.; Matteau-Pelletier, C.; Lam, T.; Saboural, P.; Kakkar, A.K.; Lesage, F.; Rhéaume, E.; Tardif, J.C. VCAM-1-targeting gold nanoshell probe for photoacoustic imaging of atherosclerotic plaque in mice. Contrast Media Mol. Imaging 2013, 8, 27-39. [CrossRef] [PubMed]

105. Leung, K. Polyethylene glycol-coated gold nanoshells conjugated with anti-VCAM-1 antibody. In Molecular Imaging and Contrast Agent Database (MICAD); National Center for Biotechnology Information (US): Bethesda, MD, USA, 2013.

106. Jang, I.-K.; Bouma, B.E.; Kang, D.-H.; Park, S.-J.; Park, S.-W.; Seung, K.-B.; Choi, K.-B.; Shishkov, M.; Schlendorf, K.; Pomerantsev, E. Visualization of coronary atherosclerotic plaques in patients using optical coherence tomography: Comparison with intravascular ultrasound. J. Am. Coll. Cardiol. 2002, 39, 604-609. [CrossRef]

107. Yelbuz, T.M.; Choma, M.A.; Thrane, L.; Kirby, M.L.; Izatt, J.A. Optical coherence tomography: A new high-resolution imaging technology to study cardiac development in chick embryos. Circulation 2002, 106, 2771-2774. [CrossRef]

108. Hu, J.; Sanz-Rodríguez, F.; Rivero, F.; Rodríguez, E.M.; Torres, R.A.; Ortgies, D.H.; Solé, J.G.; Alfonso, F.; Jaque, D. Gold nanoshells: Contrast agents for cell imaging by cardiovascular optical coherence tomography. Nano Res. 2018, 11, 676-685. [CrossRef]

109. Van Straaten, E.; Scheltens, P.; Barkhof, F. MRI and CT in the diagnosis of vascular dementia. J. Neurol. Sci. 2004, 226, 9-12. [CrossRef]

110. Maccioni, F.; Bruni, A.; Viscido, A.; Colaiacomo, M.C.; Cocco, A.; Montesani, C.; Caprilli, R.; Marini, M. MR imaging in patients with Crohn disease: Value of T2-versus T1-weighted gadolinium-enhanced MR sequences with use of an oral superparamagnetic contrast agent. Radiology 2006, 238, 517-530. [CrossRef] [PubMed]

111. Laurent, S.; Henoumont, C.; Stanicki, D.; Boutry, S.; Lipani, E.; Belaid, S.; Muller, R.N.; Vander Elst, L. Superparamagnetic iron oxide nanoparticles. In MRI Contrast Agents; Springer: Berlin/Heidelberg, Germany, 2017; pp. 55-109.

112. Qin, M.; Peng, Y.; Xu, M.; Yan, H.; Cheng, Y.; Zhang, X.; Huang, D.; Chen, W.; Meng, Y. Uniform $\mathrm{Fe}_{3} \mathrm{O}_{4} / \mathrm{Gd}_{2} \mathrm{O}_{3}-\mathrm{DHCA}$ nanocubes for dual-mode MR imaging. Beilstein Arch. 2020, 2020, 50.

113. Jiang, W.; Rutherford, D.; Vuong, T.; Liu, H. Nanomaterials for treating cardiovascular diseases: A review. Bioact. Mater. 2017, 2, 185-198. [CrossRef] [PubMed]

114. Barani, M.; Bilal, M.; Rahdar, A.; Arshad, R.; Kumar, A.; Hamishekar, H.; Kyzas, G.Z. Nanodiagnosis and nanotreatment of colorectal cancer: An overview. J. Nanopart. Res. 2021, 23, 18. [CrossRef]

115. Barani, M.; Bilal, M.; Sabir, F.; Rahdar, A.; Kyzas, G.Z. Nanotechnology in ovarian cancer: Diagnosis and treatment. Life Sci. 2020, 266, 118914. [CrossRef]

116. Barani, M.; Mukhtar, M.; Rahdar, A.; Sargazi, G.; Thysiadou, A.; Kyzas, G.Z. Progress in the application of nanoparticles and graphene as drug carriers and on the diagnosis of brain infections. Molecules 2021, 26, 186. [CrossRef] 
117. Barani, M.; Mukhtar, M.; Rahdar, A.; Sargazi, S.; Pandey, S.; Kang, M. Recent advances in nanotechnology-based diagnosis and treatments of human osteosarcoma. Biosensors 2021, 11, 55. [CrossRef]

118. Ghazy, E.; Kumar, A.; Barani, M.; Kaur, I.; Rahdar, A.; Behl, T. Scrutinizing the therapeutic and diagnostic potential of nanotechnology in thyroid cancer: Edifying drug targeting by nano-oncotherapeutics. J. Drug Deliv. Sci. Technol. 2020, 61, 102221. [CrossRef]

119. Hasanein, P.; Rahdar, A.; Barani, M.; Baino, F.; Yari, S. Oil-in-water microemulsion encapsulation of antagonist drugs prevents renal ischemia-reperfusion injury in rats. Appl. Sci. 2021, 11, 1264. [CrossRef]

120. Mukhtar, M.; Bilal, M.; Rahdar, A.; Barani, M.; Arshad, R.; Behl, T.; Brisc, C.; Banica, F.; Bungau, S. Nanomaterials for diagnosis and treatment of brain cancer: Recent updates. Chemosensors 2020, 8, 117. [CrossRef]

121. Qindeel, M.; Barani, M.; Rahdar, A.; Arshad, R.; Cucchiarini, M. Nanomaterials for the diagnosis and treatment of urinary tract infections. Nanomaterials 2021, 11,546. [CrossRef]

122. Rahdar, A.; Hajinezhad, M.R.; Sargazi, S.; Bilal, M.; Barani, M.; Karimi, P.; Kyzas, G.Z. Biochemical effects of deferasirox and deferasirox-loaded nanomicellesin iron-intoxicated rats. Life Sci. 2021, 270, 119146. [CrossRef]

123. Rahdar, A.; Sargazi, S.; Barani, M.; Shahraki, S.; Sabir, F.; Aboudzadeh, M.A. Lignin-stabilized doxorubicin microemulsions: Synthesis, physical characterization, and in vitro assessments. Polymers 2021, 13, 641. [CrossRef]

124. Sabir, F.; Barani, M.; Rahdar, A.; Bilal, M.; Nadeem, M. How to face skin cancer with nanomaterials: A review. Biointerface Res. Appl. Chem. 2021, 11, 11931-11955.

125. Bao, L.; You, B.; Shi, S.; Shan, Y.; Zhang, Q.; Yue, H.; Zhang, J.; Zhang, W.; Shi, Y.; Liu, Y. Metastasis-associated miR-23a from nasopharyngeal carcinoma-derived exosomes mediates angiogenesis by repressing a novel target gene TSGA10. Oncogene 2018, 37, 2873-2889. [CrossRef]

126. Wang, K.; Li, Y.-F.; Lv, Q.; Li, X.-M.; Dai, Y.; Wei, Z.-F. Bergenin, acting as an agonist of PPAR $\gamma$, ameliorates experimental colitis in mice through improving expression of SIRT1, and therefore inhibiting NF-kB-mediated macrophage activation. Front. Pharmacol. 2018, 8, 981. [CrossRef] [PubMed]

127. Elsabahy, M.; Wooley, K.L. Design of polymeric nanoparticles for biomedical delivery applications. Chem. Soc. Rev. 2012, 41, 2545-2561. [CrossRef] [PubMed]

128. Vimbela, G.V.; Ngo, S.M.; Fraze, C.; Yang, L.; Stout, D.A. Antibacterial properties and toxicity from metallic nanomaterials. Int. J. Nanomed. 2017, 12, 3941. [CrossRef] [PubMed]

129. Cagel, M.; Tesan, F.C.; Bernabeu, E.; Salgueiro, M.J.; Zubillaga, M.B.; Moretton, M.A.; Chiappetta, D.A. Polymeric mixed micelles as nanomedicines: Achievements and perspectives. Eur. J. Pharm. Biopharm. 2017, 113, 211-228. [CrossRef] [PubMed]

130. Wang, X.-F.; Xiao, H.; Chen, P.-Z.; Yang, Q.-Z.; Chen, B.; Tung, C.-H.; Chen, Y.-Z.; Wu, L.-Z. Pure organic room temperature phosphorescence from excited dimers in self-assembled nanoparticles under visible and near-infrared irradiation in water. J. Am. Chem. Soc. 2019, 141, 5045-5050. [CrossRef] [PubMed]

131. Yu, Y.; Shi, Y.; Zhang, B. Synergetic transformation of solid inorganic-organic hybrids into advanced nanomaterials for catalytic water splitting. Acc. Chem. Res. 2018, 51, 1711-1721. [CrossRef]

132. Pala, R.; Pattnaik, S.; Busi, S.; Nauli, S.M. Nanomaterials as novel cardiovascular theranostics. Pharmaceutics 2021, 13 , 348. [CrossRef]

133. Nicolosi, D.; Scalia, M.; Nicolosi, V.M.; Pignatello, R. Encapsulation in fusogenic liposomes broadens the spectrum of action of vancomycin against Gram-negative bacteria. Int. J. Antimicrob. Agents 2010, 35, 553-558. [CrossRef] [PubMed]

134. Darwitan, A.; Wong, Y.S.; Nguyen, L.T.; Czarny, B.; Vincent, A.; Nedumaran, A.M.; Tan, Y.F.; Muktabar, A.; Tang, J.K.; Ng, K.W. Liposomal nanotherapy for treatment of atherosclerosis. Adv. Healthc. Mater. 2020, 9, 2000465. [CrossRef]

135. Matoba, T.; Koga, J.-I.; Nakano, K.; Egashira, K.; Tsutsui, H. Nanoparticle-mediated drug delivery system for atherosclerotic cardiovascular disease. J. Cardiol. 2017, 70, 206-211. [CrossRef] [PubMed]

136. Dasa, S.S.K.; Suzuki, R.; Gutknecht, M.; Brinton, L.T.; Tian, Y.; Michaelsson, E.; Lindfors, L.; Klibanov, A.L.; French, B.A.; Kelly, K.A. Development of target-specific liposomes for delivering small molecule drugs after reperfused myocardial infarction. $J$. Control. Release 2015, 220, 556-567. [CrossRef] [PubMed]

137. Lestini, B.J.; Sagnella, S.M.; Xu, Z.; Shive, M.S.; Richter, N.J.; Jayaseharan, J.; Case, A.J.; Kottke-Marchant, K.; Anderson, J.M.; Marchant, R.E. Surface modification of liposomes for selective cell targeting in cardiovascular drug delivery. J. Control. Release 2002, 78, 235-247. [CrossRef]

138. Van der Valk, F.M.; van Wijk, D.F.; Lobatto, M.E.; Verberne, H.J.; Storm, G.; Willems, M.C.; Legemate, D.A.; Nederveen, A.J.; Calcagno, C.; Mani, V. Prednisolone-containing liposomes accumulate in human atherosclerotic macrophages upon intravenous administration. Nanomed. Nanotechnol. Biol. Med. 2015, 11, 1039-1046. [CrossRef] [PubMed]

139. Laing, S.T.; Moody, M.R.; Kim, H.; Smulevitz, B.; Huang, S.-L.; Holland, C.K.; McPherson, D.D.; Klegerman, M.E. Thrombolytic efficacy of tissue plasminogen activator-loaded echogenic liposomes in a rabbit thrombus model. Thromb. Res. 2012, 130, 629-635. [CrossRef]

140. Zhong, H.; Deng, Y.; Wang, X.; Yang, B. Multivesicular liposome formulation for the sustained delivery of breviscapine. Int. J. Pharm. 2005, 301, 15-24. [CrossRef]

141. Huang, G.; Zhou, Z.; Srinivasan, R.; Penn, M.S.; Kottke-Marchant, K.; Marchant, R.E.; Gupta, A.S. Affinity manipulation of surface-conjugated RGD peptide to modulate binding of liposomes to activated platelets. Biomaterials 2008, 29, 1676-1685. [CrossRef] 
142. Januzzi, J.L., Jr.; Maisel, A.S.; Silver, M.; Xue, Y.; DeFilippi, C. Natriuretic peptide testing for predicting adverse events following heart failure hospitalization. Congest. Heart Fail. 2012, 18, S9-S13. [CrossRef]

143. Al Meslmani, B.M.; Mahmoud, G.F.; Bakowsky, U. Development of expanded polytetrafluoroethylene cardiovascular graft platform based on immobilization of poly lactic-co-glycolic acid nanoparticles using a wet chemical modification technique. Int. J. Pharm. 2017, 529, 238-244. [CrossRef]

144. Ahadian, S.; Huyer, L.D.; Estili, M.; Yee, B.; Smith, N.; Xu, Z.; Sun, Y.; Radisic, M. Moldable elastomeric polyester-carbon nanotube scaffolds for cardiac tissue engineering. Acta Biomater. 2017, 52, 81-91. [CrossRef] [PubMed]

145. Wennink, J.W.; Liu, Y.; Mäkinen, P.I.; Setaro, F.; de la Escosura, A.; Bourajjaj, M.; Lappalainen, J.P.; Holappa, L.P.; van den Dikkenberg, J.B.; Al Fartousi, M. Macrophage selective photodynamic therapy by meta-tetra (hydroxyphenyl) chlorin loaded polymeric micelles: A possible treatment for cardiovascular diseases. Eur. J. Pharm. Sci. 2017, 107, 112-125. [CrossRef] [PubMed]

146. Cormode, D.P.; Naha, P.C.; Fayad, Z.A. Nanoparticle contrast agents for computed tomography: A focus on micelles. Contrast Media Mol. Imaging 2014, 9, 37-52. [CrossRef] [PubMed]

147. Mosser, D.M.; Edwards, J.P. Exploring the full spectrum of macrophage activation. Nat. Rev. Immunol. 2008, 8, 958-969. [CrossRef] [PubMed]

148. Nakashiro, S.; Matoba, T.; Umezu, R.; Koga, J.-i.; Tokutome, M.; Katsuki, S.; Nakano, K.; Sunagawa, K.; Egashira, K. Pioglitazoneincorporated nanoparticles prevent plaque destabilization and rupture by regulating monocyte/macrophage differentiation in ApoE-/- mice. Arterioscler. Thromb. Vasc. Biol. 2016, 36, 491-500. [CrossRef] [PubMed]

149. Yoo, S.P.; Pineda, F.; Barrett, J.C.; Poon, C.; Tirrell, M.; Chung, E.J. Gadolinium-functionalized peptide amphiphile micelles for multimodal imaging of atherosclerotic lesions. ACS Omega 2016, 1, 996-1003. [CrossRef]

150. Kirana, C.; Rogers, P.F.; Bennett, L.E.; Abeywardena, M.Y.; Patten, G.S. Naturally derived micelles for rapid in vitro screening of potential cholesterol-lowering bioactives. J. Agric. Food Chem. 2005, 53, 4623-4627. [CrossRef] [PubMed]

151. Wang, S.; Wang, S.; Yu, X.; Zeng, J.; Li, H.; Yang, R.; Chen, W.; Dong, J. Magnetic nanoparticles functionalized with immobilized apolipoprotein antibodies for direct detection of non-high density lipoprotein cholesterol in human serum. Chem. Eng. J. 2020, 385, 123465. [CrossRef]

152. A Sharma, P.; Maheshwari, R.; Tekade, M.; Kumar Tekade, R. Nanomaterial based approaches for the diagnosis and therapy of cardiovascular diseases. Curr. Pharm. Des. 2015, 21, 4465-4478. [CrossRef]

153. Kievit, F.M.; Veiseh, O.; Fang, C.; Bhattarai, N.; Lee, D.; Ellenbogen, R.G.; Zhang, M. Chlorotoxin labeled magnetic nanovectors for targeted gene delivery to glioma. ACS Nano 2010, 4, 4587-4594. [CrossRef] [PubMed]

154. Ito, A.; Shinkai, M.; Honda, H.; Kobayashi, T. Medical application of functionalized magnetic nanoparticles. J. Biosci. Bioeng. 2005, 100, 1-11. [CrossRef]

155. Mouli, S.K.; Tyler, P.; McDevitt, J.L.; Eifler, A.C.; Guo, Y.; Nicolai, J.; Lewandowski, R.J.; Li, W.; Procissi, D.; Ryu, R.K. Image-guided local delivery strategies enhance therapeutic nanoparticle uptake in solid tumors. ACS Nano 2013, 7, 7724-7733. [CrossRef] [PubMed]

156. Chen, C.-C.; Lin, Y.-P.; Wang, C.-W.; Tzeng, H.-C.; Wu, C.-H.; Chen, Y.-C.; Chen, C.-P.; Chen, L.-C.; Wu, Y.-C. DNA- gold nanorod conjugates for remote control of localized gene expression by near infrared irradiation. J. Am. Chem. Soc. 2006, 128, 3709-3715. [CrossRef]

157. Chithrani, B.D.; Chan, W.C. Elucidating the mechanism of cellular uptake and removal of protein-coated gold nanoparticles of different sizes and shapes. Nano Lett. 2007, 7, 1542-1550. [CrossRef]

158. Ghann, W.E.; Aras, O.; Fleiter, T.; Daniel, M.-C. Syntheses and characterization of lisinopril-coated gold nanoparticles as highly stable targeted CT contrast agents in cardiovascular diseases. Langmuir 2012, 28, 10398-10408. [CrossRef]

159. Almutairi, A.; Rossin, R.; Shokeen, M.; Hagooly, A.; Ananth, A.; Capoccia, B.; Guillaudeu, S.; Abendschein, D.; Anderson, C.J.; Welch, M.J. Biodegradable dendritic positron-emitting nanoprobes for the noninvasive imaging of angiogenesis. Proc. Natl. Acad. Sci. USA 2009, 106, 685-690. [CrossRef]

160. Lu, Y.; Sun, B.; Li, C.; Schoenfisch, M.H. Structurally diverse nitric oxide-releasing poly(propylene imine) dendrimers. Chem. Mater. 2011, 23, 4227-4233. [CrossRef]

161. Tomalia, D.A. Starburstŕ dendrimers-Nanoscopic supermolecules according to dendritic rules and principles. In Macromolecular Symposia; Hüthig \& Wepf Verlag: Basel, Switzerland; pp. 243-255.

162. Venkatesh, S.; Li, M.; Saito, T.; Tong, M.; Rashed, E.; Mareedu, S.; Zhai, P.; Bárcena, C.; López-Otín, C.; Yehia, G.; et al. Mitochondrial LonP1 protects cardiomyocytes from ischemia/reperfusion injury in vivo. J. Mol. Cell. Cardiol. 2019, 128, 38-50. [CrossRef]

163. Taite, L.J.; West, J.L. Poly (ethylene glycol)-lysine dendrimers for targeted delivery of nitric oxide. J. Biomater. Sci. Polym. Ed. 2006, 17, 1159-1172. [CrossRef]

164. Bhadra, D.; Bhadra, S.; Jain, N.K. Pegylated lysine based copolymeric dendritic micelles for solubilization and delivery of artemether. J. Pharm. Pharm. Sci. Publ. Can. Soc. Pharm. Sci. Soc. Can. Des Sci. Pharm. 2005, 8, 467-482.

165. Shao, W.; Arghya, P.; Yiyong, M.; Rodes, L.; Prakash, S. Carbon nanotubes for use in medicine: Potentials and limitations. Synth. Appl. Carbon Nanotub. Compos. 2013, 13, 285-311.

166. Chen, Z.; Zhang, X.; Yang, R.; Zhu, Z.; Chen, Y.; Tan, W. Single-walled carbon nanotubes as optical materials for biosensing. Nanoscale 2011, 3, 1949-1956. [CrossRef] 
167. Strus, M.C.; Chiaramonti, A.N.; Kim, Y.L.; Jung, Y.J.; Keller, R.R. Accelerated reliability testing of highly aligned single-walled carbon nanotube networks subjected to DC electrical stressing. Nanotechnology 2011, 22, 265713. [CrossRef]

168. Garibaldi, S.; Brunelli, C.; Bavastrello, V.; Ghigliotti, G.; Nicolini, C. Carbon nanotube biocompatibility with cardiac muscle cells. Nanotechnology 2005, 17, 391. [CrossRef]

169. Jayagopal, A.; Russ, P.K.; Haselton, F.R. Surface engineering of quantum dots for in vivo vascular imaging. Bioconjugate Chem. 2007, 18, 1424-1433. [CrossRef] [PubMed]

170. Larson, D.R.; Zipfel, W.R.; Williams, R.M.; Clark, S.W.; Bruchez, M.P.; Wise, F.W.; Webb, W.W. Water-soluble quantum dots for multiphoton fluorescence imaging in vivo. Science 2003, 300, 1434-1436. [CrossRef]

171. Ferrara, D.E.; Glaus, C.; Taylor, W.R. Targeting vascular epitopes using quantum dots. In Nanoparticles in Biomedical Imaging; Springer: Berlin/Heidelberg, Germany, 2008; pp. 443-461.

172. Yan, M.; Zhang, Y.; Xu, K.; Fu, T.; Qin, H.; Zheng, X. An in vitro study of vascular endothelial toxicity of CdTe quantum dots. Toxicology 2011, 282, 94-103. [CrossRef]

173. Aizik, G.; Waiskopf, N.; Agbaria, M.; Ben-David-Naim, M.; Levi-Kalisman, Y.; Shahar, A.; Banin, U.; Golomb, G. Liposomes of quantum dots configured for passive and active delivery to tumor tissue. Nano Lett. 2019, 19, 5844-5852. [CrossRef] [PubMed]

174. Parmin, N.A.; Hashim, U.; Gopinath, S.C.; Nadzirah, S.; Uda, M.; Uda, M.A.; Hong, V.; Yaakub, A.R.W. Diagnosing metabolic diseases by nanoparticle immobilization. In Nanoparticles in Analytical and Medical Devices; Elsevier: Amsterdam, The Netherlands, 2021; pp. 211-222.

175. Liu, Q.; Piao, H.; Wang, Y.; Zheng, D.; Wang, W. Circulating exosomes in cardiovascular disease: Novel carriers of biological information. Biomed. Pharmacother. 2021, 135, 111148. [CrossRef] [PubMed]

176. Boonkaew, S.; Jang, I.; Noviana, E.; Siangproh, W.; Chailapakul, O.; Henry, C.S. Electrochemical paper-based analytical device for multiplexed, point-of-care detection of cardiovascular disease biomarkers. Sens. Actuators B Chem. 2021, 330, 129336. [CrossRef]

177. Bose, R.J.; Ha, K.; McCarthy, J.R. Bio-inspired nanomaterials as novel options for the treatment of cardiovascular disease. Drug Discov. Today 2021. [CrossRef]

178. Cheng, M.; Liu, Q.; Liu, W.; Yuan, F.; Feng, J.; Jin, Y.; Tu, L. Engineering micelles for the treatment and diagnosis of atherosclerosis. J. Drug Deliv. Sci. Technol. 2021, 63, 102473. [CrossRef]

179. Sim, S.; Wong, N.K. Nanotechnology and its use in imaging and drug delivery. Biomed. Rep. 2021, 14, 1-9. [CrossRef]

180. Sha, X.; Dai, Y.; Song, X.; Liu, S.; Zhang, S.; Li, J. The opportunities and challenges of silica nanomaterial for atherosclerosis. Int. J. Nanomed. 2021, 16, 701. [CrossRef] 